\title{
Problem of Hips. Children - Dysplasia. Adults - "Imperfect Hips" and Arthrosis. Methods of Prophylaxis and Therapy in Every Age
}

\author{
Karski Tomasz ${ }^{1}$, Karski Jacek ${ }^{2}$ \\ ${ }^{1}$ Vincent Pol University in Lublin, Poland. \\ ${ }^{2}$ Medical University in Lublin, Poland. \\ tmkarski@gmail.com; jkarski@vp.pl
}

*Corresponding Author: Karski Tomasz, Vincent Pol University in Lublin, Poland.

\begin{abstract}
The hip joint is a specially important in human body because of anatomical and functional specific properties. Proper hip joint need perfect anatomical building, sufficient deep acetabulum, proper roof with proper Hilgenreiner's angle and full range of movements in six directions. These rules are important for every day of activity of everybody in every age of life. Dysplasia of the hips is mostly observed in cases with "Syndrome of Contracture" (SofC) according to Prof. Hans Mau (originally in German "Siebenersyndrom" - in English "Syndrome of seven Contractures"). From 2006 we speak in Lublin about eighths deformities in SofC, its mean, about varus deformity of shanks (T. Karski) and we speak about "Syndrome of Contractures and Deformities" (SofCD).

The dysplasia is connected with SofCD in $90 \%$ of cases, and mostly is in left hip. It happened because the fetus is placed on the left side of mother's uterus in $90 \%$ or $95 \%$ of cases and undergo of mechanical influenced pressure on their left side. Other $10 \%$ of hip dysplasia is connected with "general laxity of joints". Every case of hips dysplasia in children should be entire / total / complete cured, what will be important for whole life of everybody. When is not cured enough, in next years of life can occur arthrosis in the left hip joint.

The pain problem of right hip is connected is with habit of "Standing 'at ease' on the Right Leg" (the new syndrome - T. Karski, 1997).

In both group of hip problems the prophylaxis is simply and easy. In problem of left hip - it is important the fully treatment of dysplasia in children. In problem of right hip joint - we should avoid standing on the right leg and care for full movement of this hip joint.

The procedure of prophylaxis of "imperfect hips" - painfully degenerative hips - is relative easy and not complicated for everybody, but must be introduced in early period of life, in age of $40-50$. The article present with details the methods of therapy and prophylaxis in every age of the patients, for children, for youth and for adults.
\end{abstract}

Keywords: Dysplasia of hips. Arthrosis of hips. Therapy. Prevention.

\section{INTRODUCTION}

The article is based on the material from Paediatric Orthopaedic and Rehabilitation Department (children) and from Out-Patient Clinic (youth and adults patients) in the years 1995 - 2018. Authors present the problems of diagnosis and methods of therapy of hip dysplasia in children and of insufficiency of the hips in adults. In the article is presented the "Lublin methods" of therapy of hip dysplasia in children and method of prophylaxis of arthrosis of hips by adults. Authors gives rules of conservative treatment in the incipience period of hp's arthrosis. The "pain syndrome" before 
Problem of Hips. Children - Dysplasia. Adults - "Imperfect Hips" and Arthrosis. Methods of Prophylaxis and Therapy in Every Age

the radiological symptoms of arthrosis on the left hip is a results of not fully cured dysplasia, or in the right hip as result of "Syndrome of Permanent Standing 'at ease' on the Right Leg" ([SofSRL] - T. Karski, 1997).

\section{Children - Hip Dysplasia. Prophylaxis. Therapy}

The dysplasia of the hips can occur in "Syndrome of Contractures and Deformities" (Hans Mau) in Lublin material at $90 \%$ of cases, in syndrome of laxity of joints in Lublin material at $10 \%$. SofCD appear when the child has not enough space in uterus in fetal period of life. Mostly, it is left sided SofCD what was mentioned earlier. In these cases the abduction of the hip is limited, and it is the important symptom of dysplasia (Fig. 1a, 1b, 2a, 2b). Also in X-ray picture there are observed oblique position of pelvis and typical changes for dysplasia (Fig. 3, 4). The beginning of treatment of dysplasia of the hips should start in 1st week of life according to proposal of Ortolani, Vizkelety, Bjerkreim, Papp, Rigo, Szepesi, Meszaros, Dega, Szulc, Piatkowski, Wośko, Karski \& Karski and others [1] [2] [3] [3] [4] [5] [6] [7]. In this early treatment very important is nurseling of the child face to face - with full abduction and full flexion of the hips (Fig. 5a, 5b). In first year of life we advise also to use the orthopaedic "abduction devices", such as Frejka pillow, Weickert treasures or other (Fig. 6a, 6b). For the children with dislocated hips we use in Lublin the conservative method of reduction described in www. ortopedia.karski.lublin.pl

Our recommendation of prophylaxis stay in contrary to "modern", very popular in our time, incorrect recommendation of many wrong educated doctors. They advice to "the carry the child with his face to street and to shops" (Fig. 7a, 7b, 7c).

Here we stress - only early treatment of hips can protect before "imperfect hips" (painful hips, with small or bigger radiological changes in joints) and full arthrosis symptoms in adults age.

The first year of life of the children is a specially important for proper hip development. The treatment should be proper and long lasting.

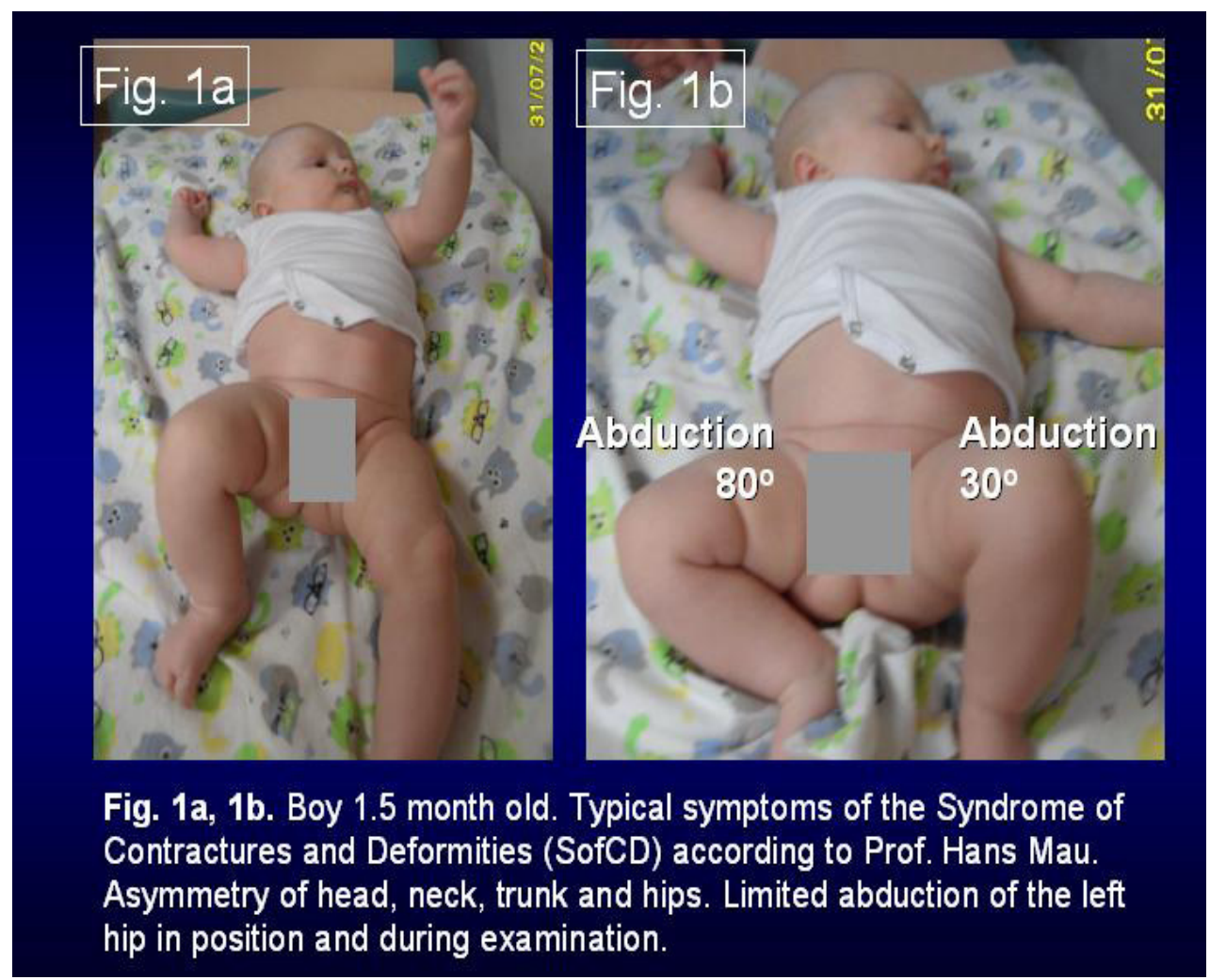

Fig 1a, 1b. Boy 1.5 month old. Typical symptoms of Syndrome of Contractures and Deformities (SofCD) according to Prof. Hans Mau. Asymmetry of head, neck, trunk and hips. Limited abduction of the left hip in position and during examination. 
Problem of Hips. Children - Dysplasia. Adults - "Imperfect Hips" and Arthrosis. Methods of Prophylaxis and Therapy in Every Age

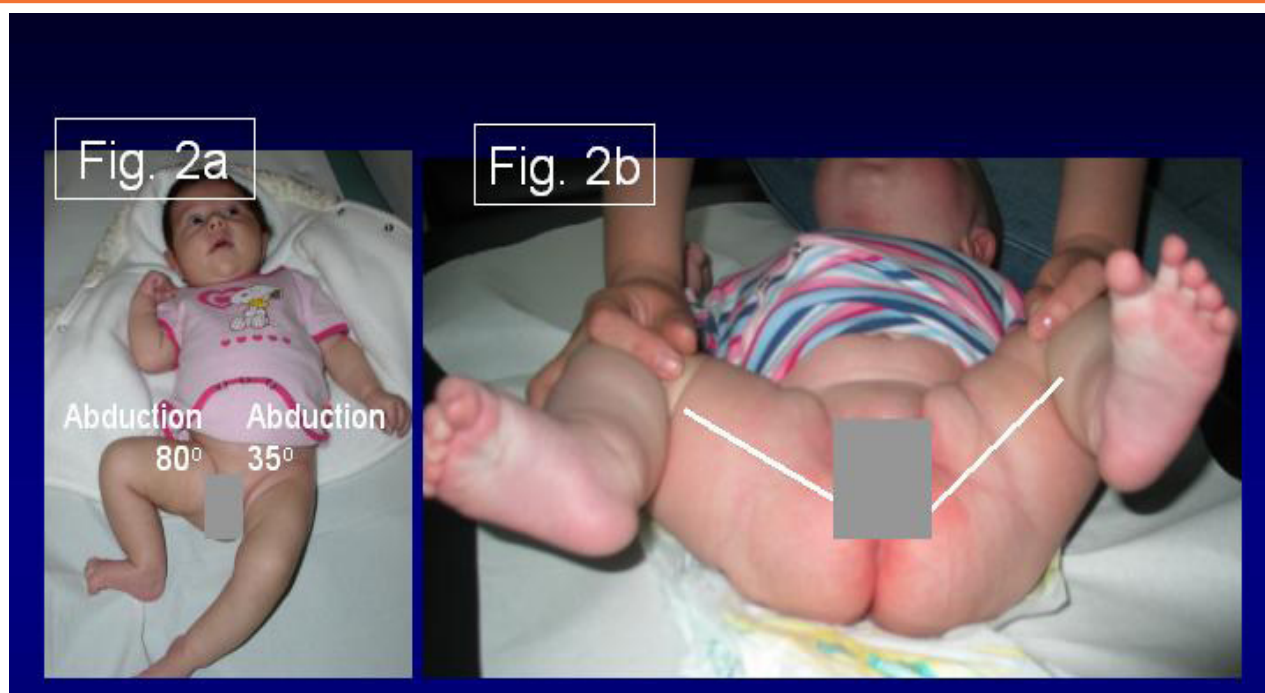

Fig. 2a, 2b. Two children. Fig. $2 \mathrm{a}$ in age of 10 month. Fig. $2 \mathrm{~b}$ in age of 3 month. Typical clinical symptoms of Syndrome of Contracture and Deformities (SofCD). Limited abduction of the left in position and during examination, as a symptom of one of the eight asymmetries in the SofCD

Fig 2a, 2b. Two children. Fig. 2a in age of 10 month. Fig. $\mathbf{2 b}$ in age of 3 month. Typical clinical symptoms of Syndrome of Contracture and Deformities (SofCD). Limited abduction of the left in position and during examination, as a symptom of one between eighths asymmetries in SofCD.

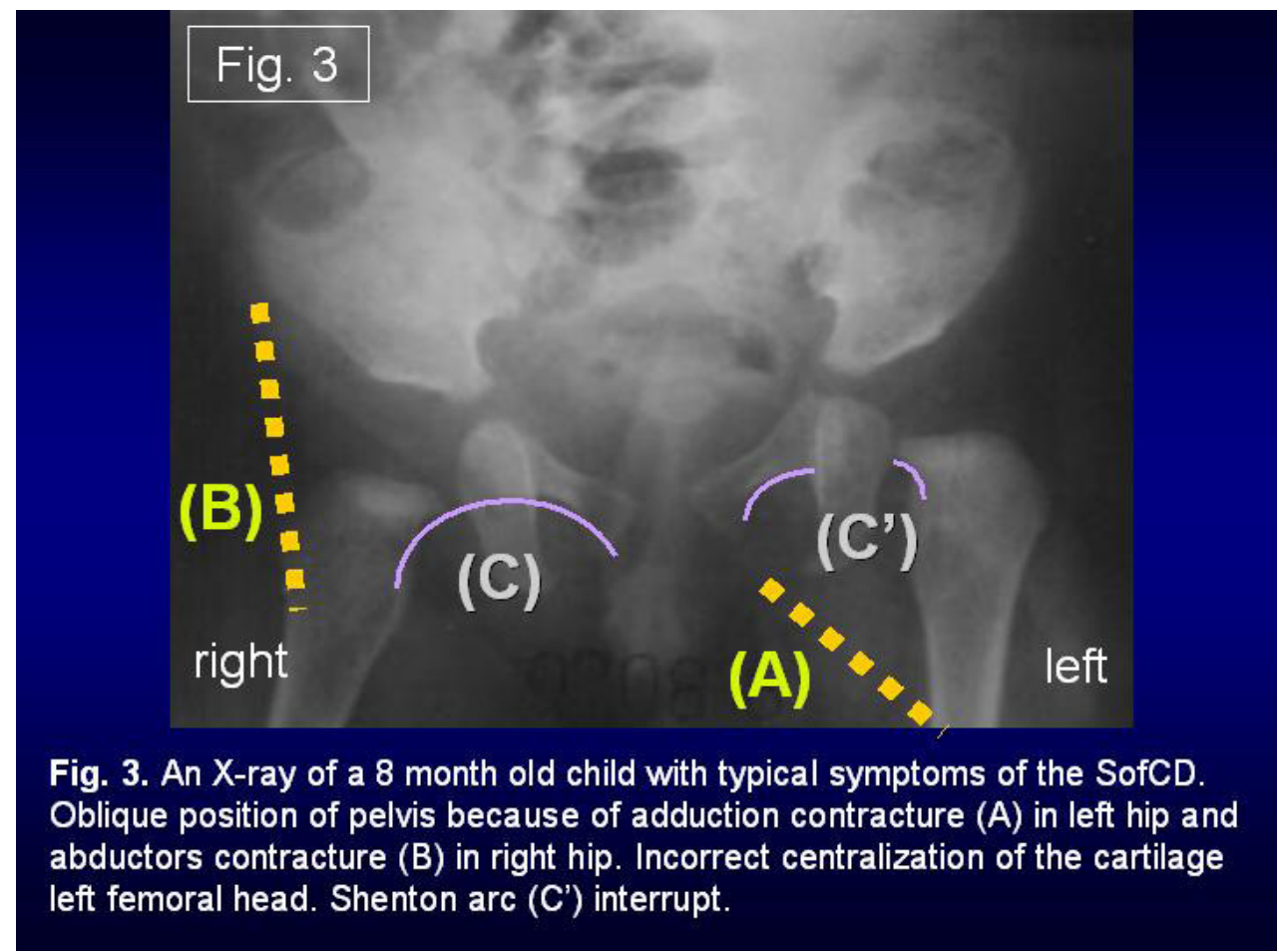

Fig 3. X-ray picture of the 8 month old child with typical symptoms of SofCD. Oblique position of pelvis because of adduction contracture (A) in left hip and abductors contracture $(\boldsymbol{B})$ in right hip. Incorrect centralization of cartilage left femoral head. Shenton arc $\left(\boldsymbol{C}^{\prime}\right)$ interrupt. 
Problem of Hips. Children - Dysplasia. Adults - "Imperfect Hips" and Arthrosis. Methods of Prophylaxis and Therapy in Every Age

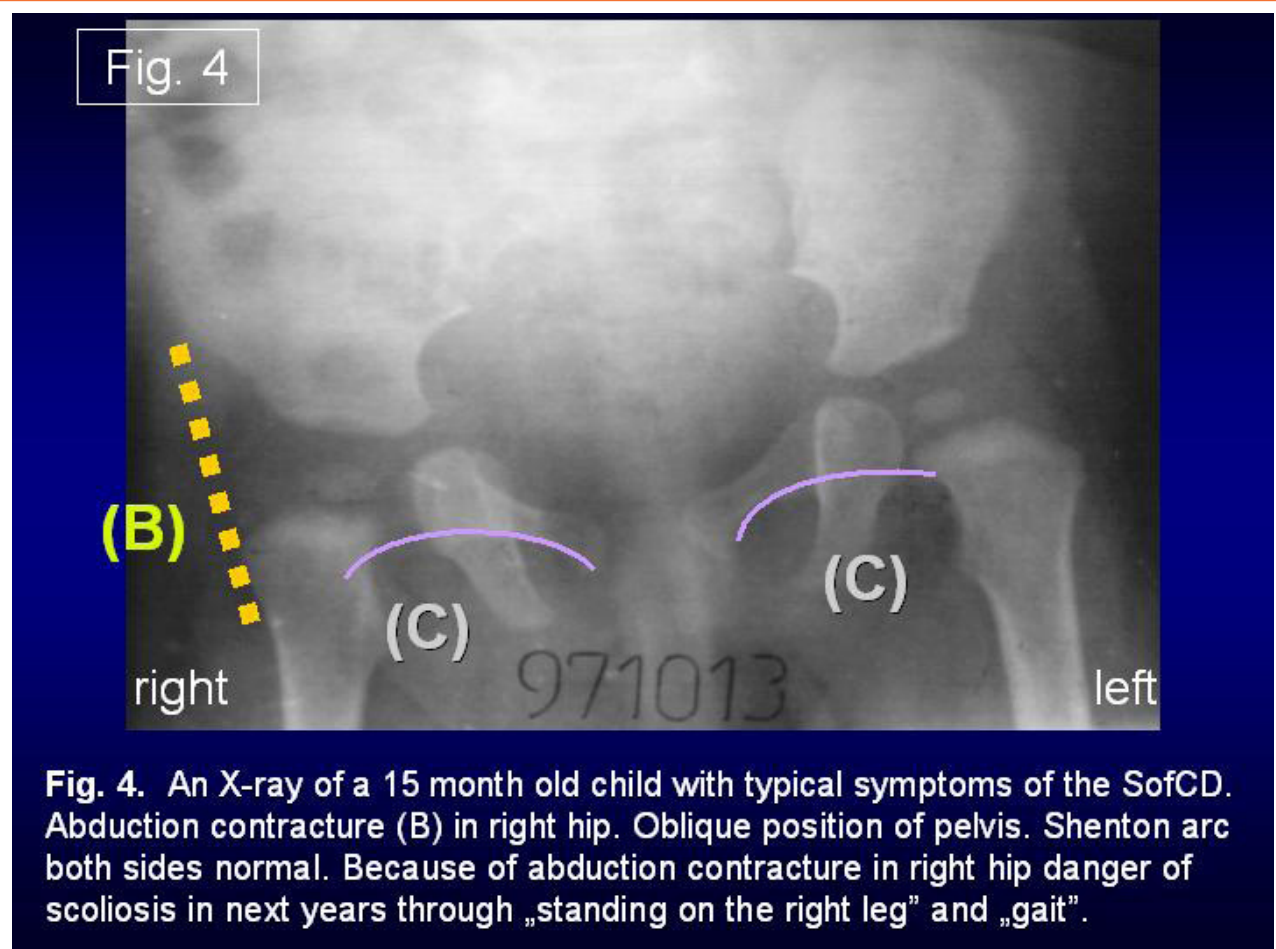

Fig 4. X-ray picture of the child 15 month old with typical symptoms of SofCD. Abduction contracture (B) in right hip. Oblique position of pelvis. Shenton arc both sides normal. Because of abduction contracture in right hip danger of scoliosis in next years through "standing on the right leg" and "gait".
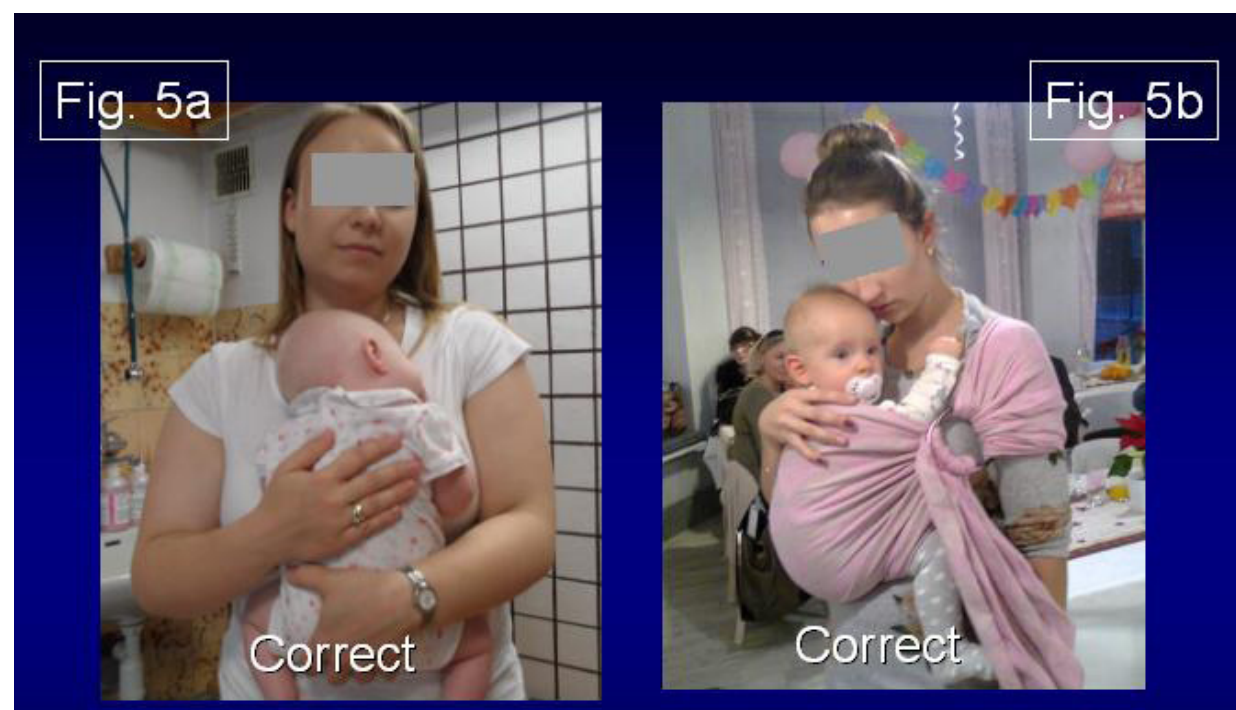

Fig. 5a, 5b. Two children. Fig. 5a - 2 months old. Fig. 5b - one year old. A proper way carrying the child with a full abduction and flexion of the hips. The best method of preventing hip dysplasia. It is important for the proper development and functioning of the hips not only in childhood but during the whole life.

Fig 5a, 5b. Two children. Fig. $4 \boldsymbol{a}$ in age of 2 months. Fig. $4 \mathbf{b}$ in age one year. The proper carrying of the child with full abduction and flexion of the hips. The best method of preventing of hips dysplasia. It is important for the proper development and function of the hip joints not only in childhood but in the whole life. 
Problem of Hips. Children - Dysplasia. Adults - "Imperfect Hips" and Arthrosis. Methods of Prophylaxis and Therapy in Every Age

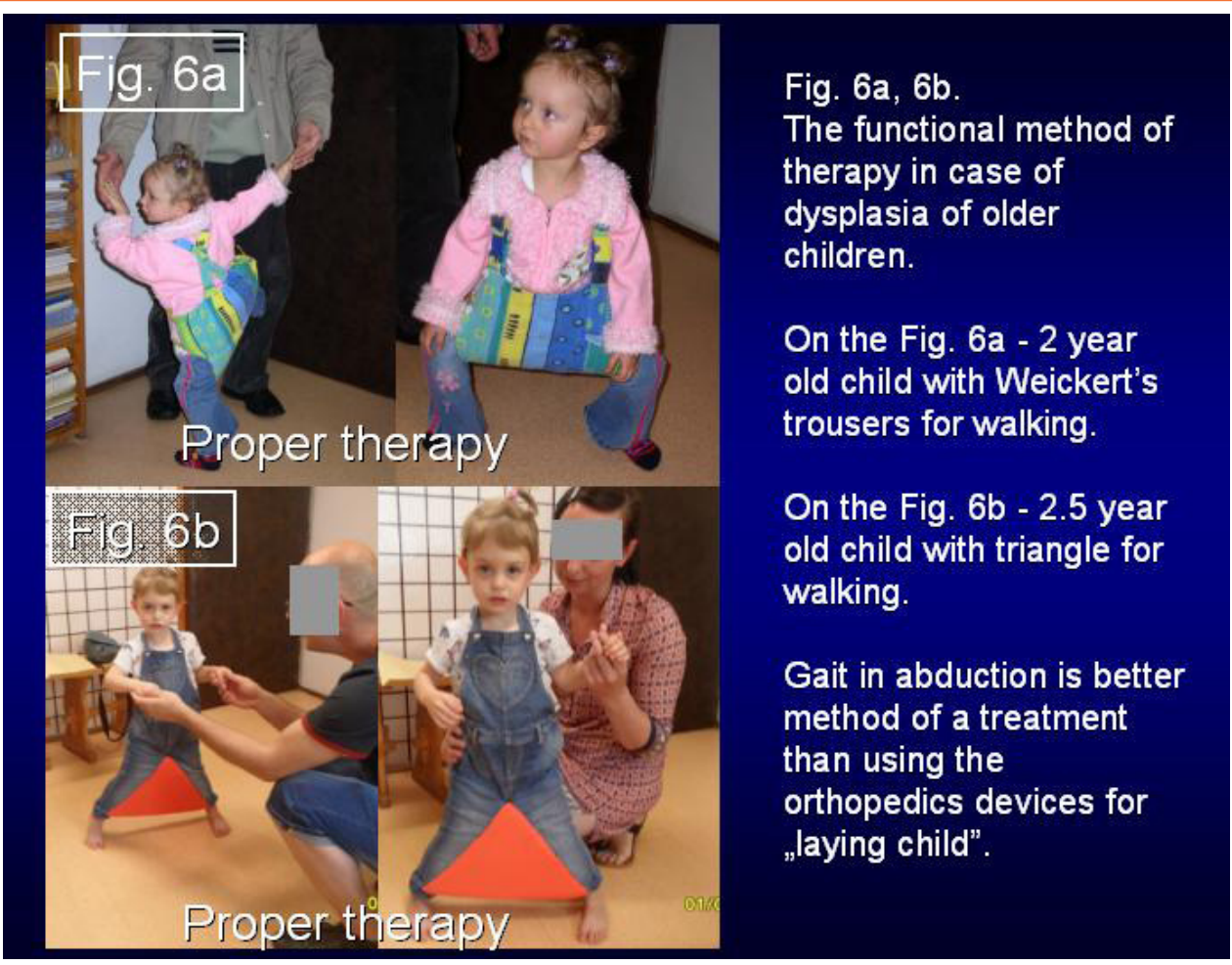

Fig 6a, 6b. The functional method of therapy in case of dysplasia of older children. On the Fig. $\mathbf{6 a}$ the child in age of 2 years with Weickert's trousers for walking. On the Fig. $\mathbf{6} \mathbf{b}$ child 2.5 years old with triangle for walking.

Gait in abduction is better method of treatment then using the orthopedics devices for down laying child.

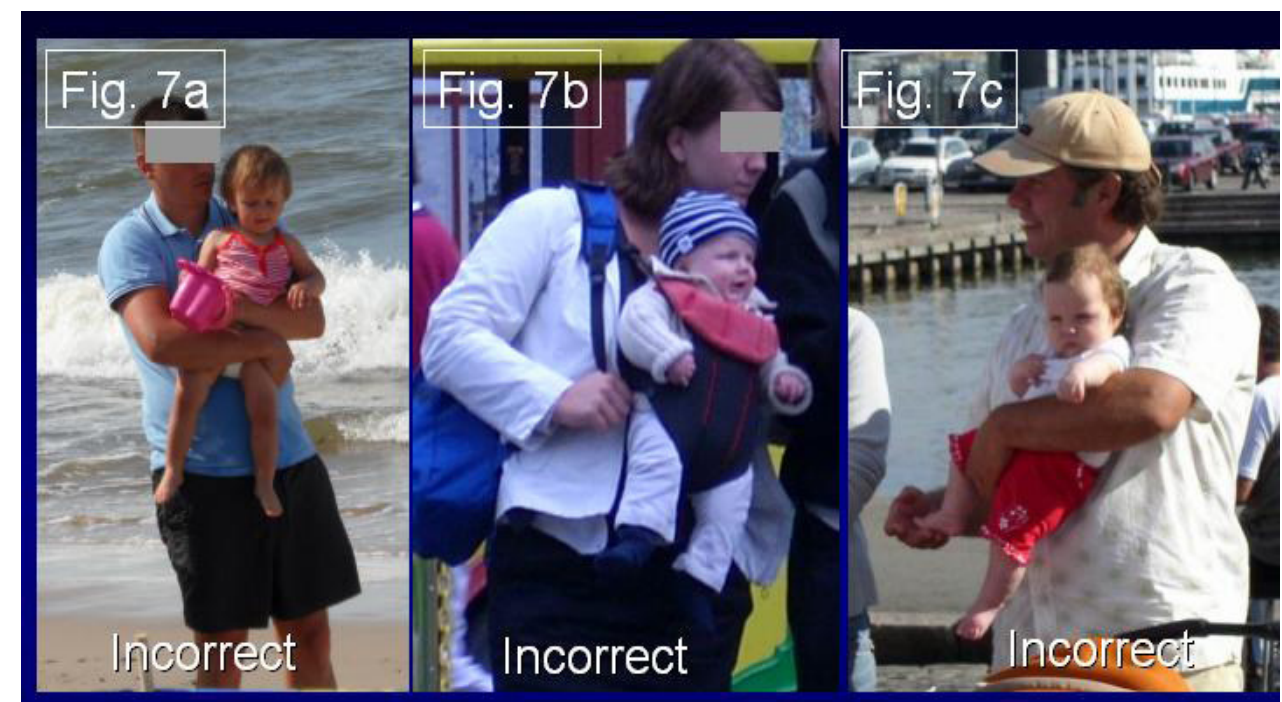

Fig. 7a, 7b, 7c. Wrong, incorrect way of carrying children. No abduction of hips. Danger of development of dysplasia. Such carrying of the child is recommended by „poorly" educated or "over - educated" doctors in many countries in Europe. Pictures taken in Poland (Fig.7a) and abroad (Fig.7b,7c).

Fig 7a, 7b, 7c. Wrong, incorrect carrying of the child. No abduction of hips. Danger of development of dysplasia. Such carrying of the child is recommended by "poorly" educated or "over - educated" doctors in many countries in Europe. Pictures taken in Poland (Fig. 7a) and abroad (Fig. 7b, 7c). 
Problem of Hips. Children - Dysplasia. Adults - "Imperfect Hips" and Arthrosis. Methods of Prophylaxis and Therapy in Every Age

\section{Material}

The patients with painful hips come for treatment to our Out Patient Clinic very often in all years of our activity. In the years $1995-2018$ it was (N) 852 cases. Age of patients 18 - 85 years. Average of age 60 years. All patients had mostly symptoms of degenerative changes in movement of whole locomotors system but on the first place it was syndromes of back pain and hip pain.

\section{Adult Patients - Symptoms of "Imperfect Hip" in the Left Hip}

The pre - arthrosis symptoms can occur in the left hip or in the right hip. In this chapter we discuss problem of left hip.

When the hip dysplasia is not fully treated can appear firstly clinical symptoms of "Imperfect Hips" next radiological changes (Fig. 8). even in age of 20 or 30 years (Fig. 9, 10). These symptoms can occur in youth period of life but more frequent, and in advanced form, in adults. There are following symptoms:

A/ Pain and restriction of abduction and internal rotation movement by the affected hip.

B/ Pain in the beginnings period of illnesses is not permanent - only in specific situations - during gait, on the street, by rapid change the direction of gait, by changing the position on chair, by standing up from chair, by going stars up or down. The pain can disappeared for some weeks or month - and this ire the patients - they think "it is no serious problem".

C/ In some patients we observe a "smaller" or "bigger" "limping". Sometimes it is only in "form of a asymmetrical time of loading". We explain there are first symptoms of arthrosis, in many cases and in this beginnings phase very often without radiological changes. They come in next years of "the processes of arthrosis" if is no introduced prophylaxis management. As we had to explain - arthrosis of left hip is mostly connected with primary hip dysplasia, not sufficiently or at all not treated in childhood period (Fig. 11, 12). The first symptoms of left sided "Imperfect Hips" appear at the age of $45-50$ (90\%). Only in a few cases in the age of $18-30(10 \%)$. The limitation of movements is typical and main symptom of development of arthrosis. Explanation: during gait - we need all movement, but especially internal rotation. Common, that this movement we lost over the life. Lack of internal rotation make irritations of soft tissues around the hip joint - comes to granuloma and disturbances of blood circulations. Step by step develop arthrosis. Firstly it is problem of painful "Imperfect hips", next we observe the arthrosis with all clinical and radiological symptoms. Such cases need surgery - prosthesis (Fig. 12).

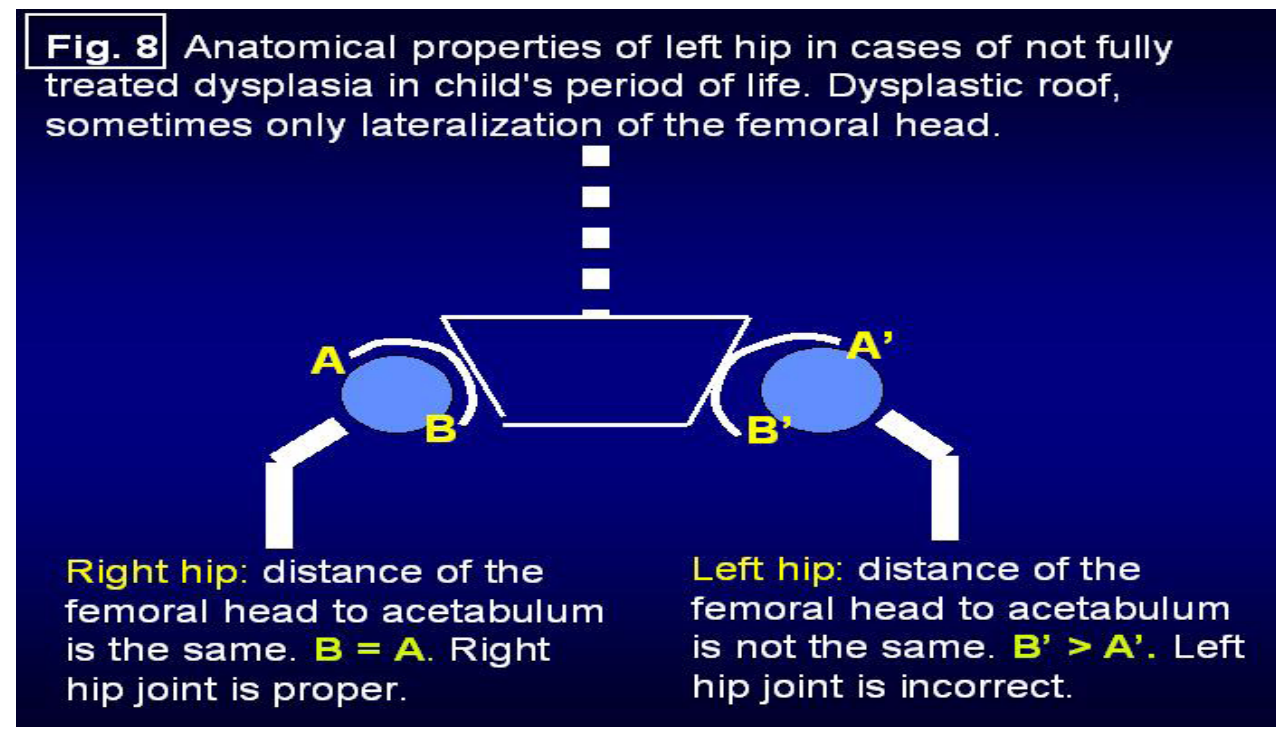

Fig 8. Anatomical properties of left hip in cases of not fully treated dysplasia in child's period of life. Dysplastic roof, sometimes only lateralization of the femoral head. Right hip: distance of the femoral head to acetabulum is the same. $B=$ A. Right hip joint is proper. Left hip: distance of the femoral head to acetabulum is not the same. $B^{\prime}>A^{\prime}$. Left hip joint is incorrect. 
Problem of Hips. Children - Dysplasia. Adults - "Imperfect Hips" and Arthrosis. Methods of Prophylaxis and Therapy in Every Age

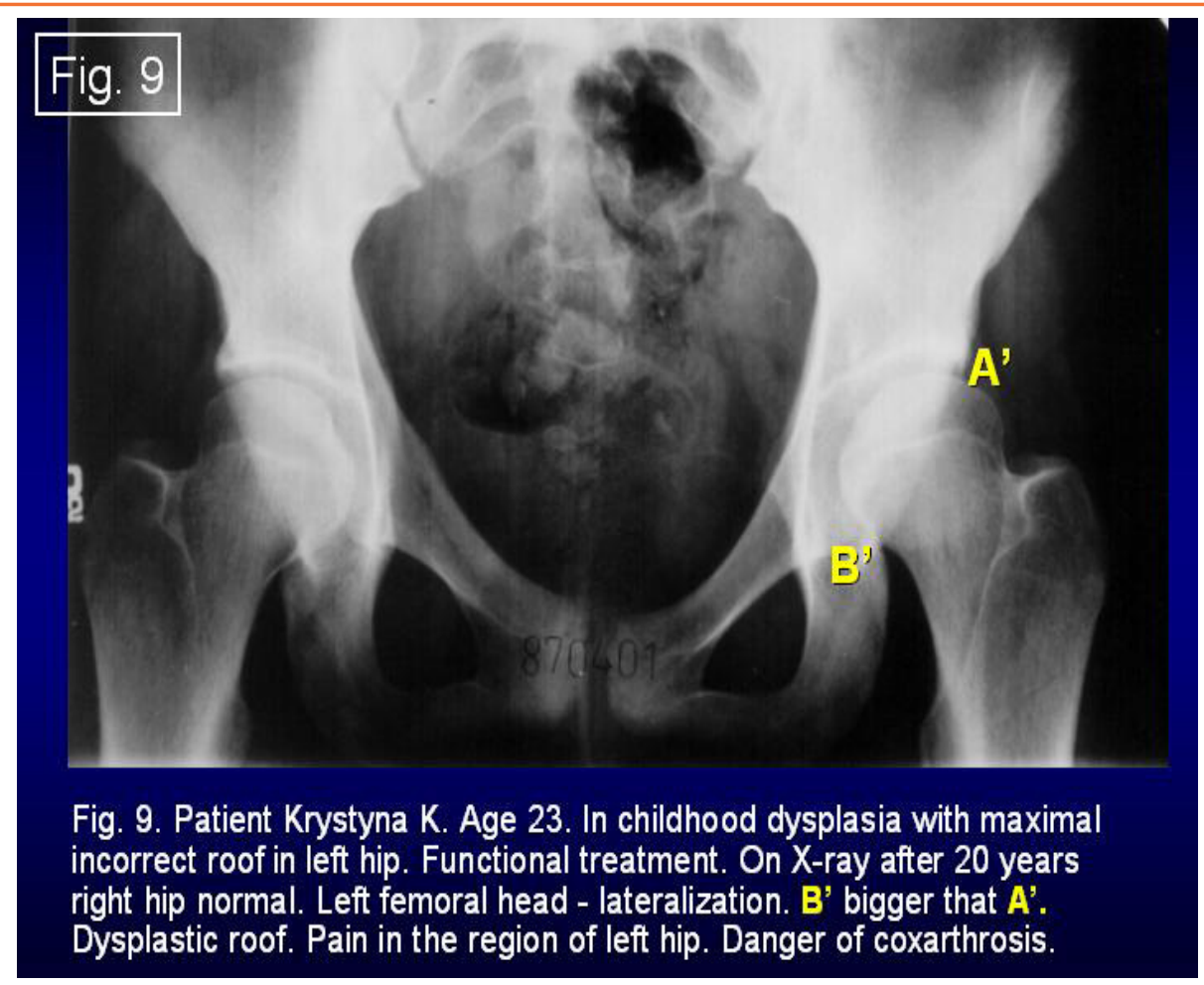

Fig 9. Patient Krystyna K. Age 23. In childhood dysplasia with maximal incorrect roof in left hip. Functional treatment. On X-ray after 20 years right hip normal. Left femoral head - lateralization. B' bigger that A'. Dysplastic roof. Pain in region of left hip. Danger of coxarthrosis.

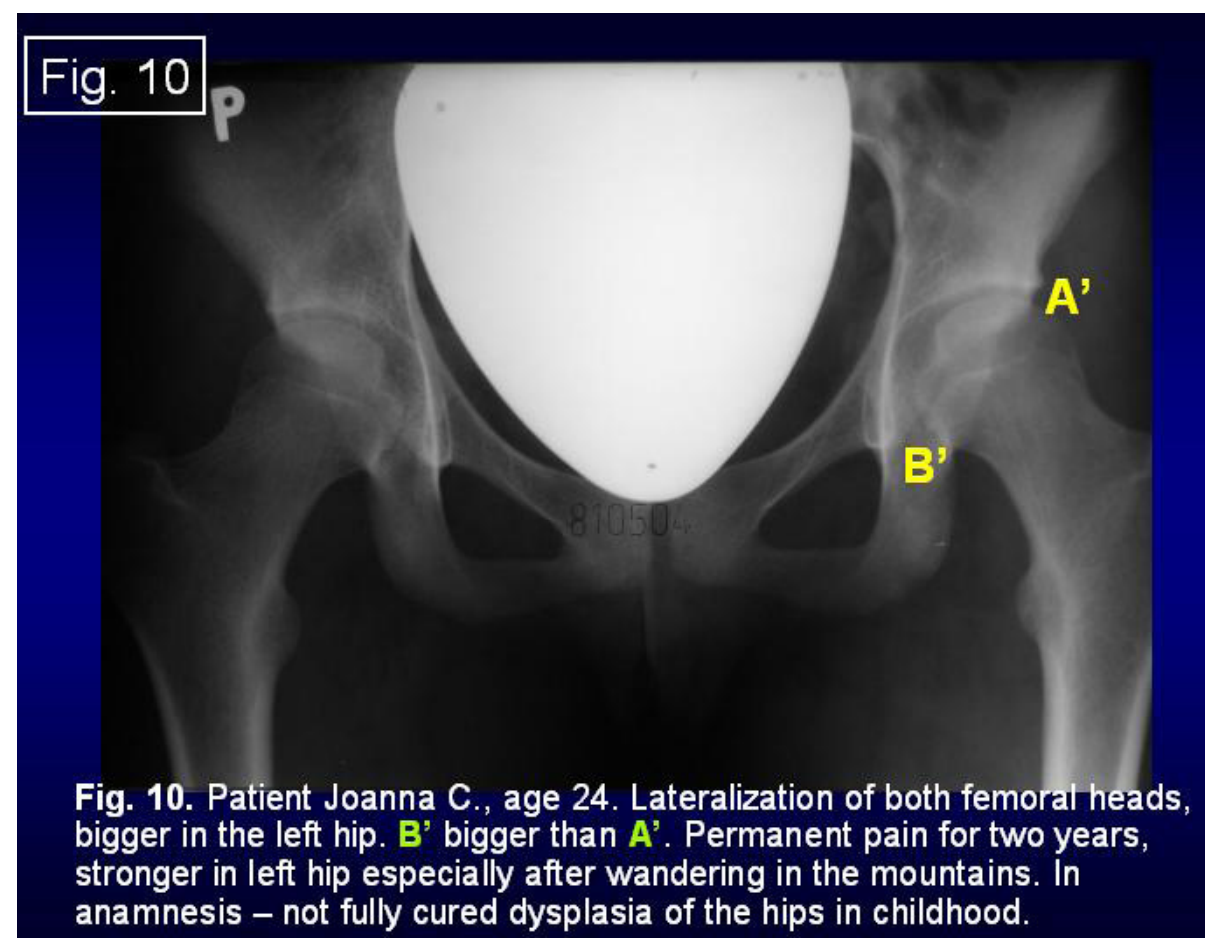

Fig 10. Patient Joanna C., age 24. Lateralization of both femoral heads, bigger in the left hip. B' bigger that A'. Permanent pain from two years, more in left hip especially after wandering in mountain. In anamnesis - not fully cured dysplasia of the hips in childhood. 
Problem of Hips. Children - Dysplasia. Adults - "Imperfect Hips" and Arthrosis. Methods of Prophylaxis and Therapy in Every Age

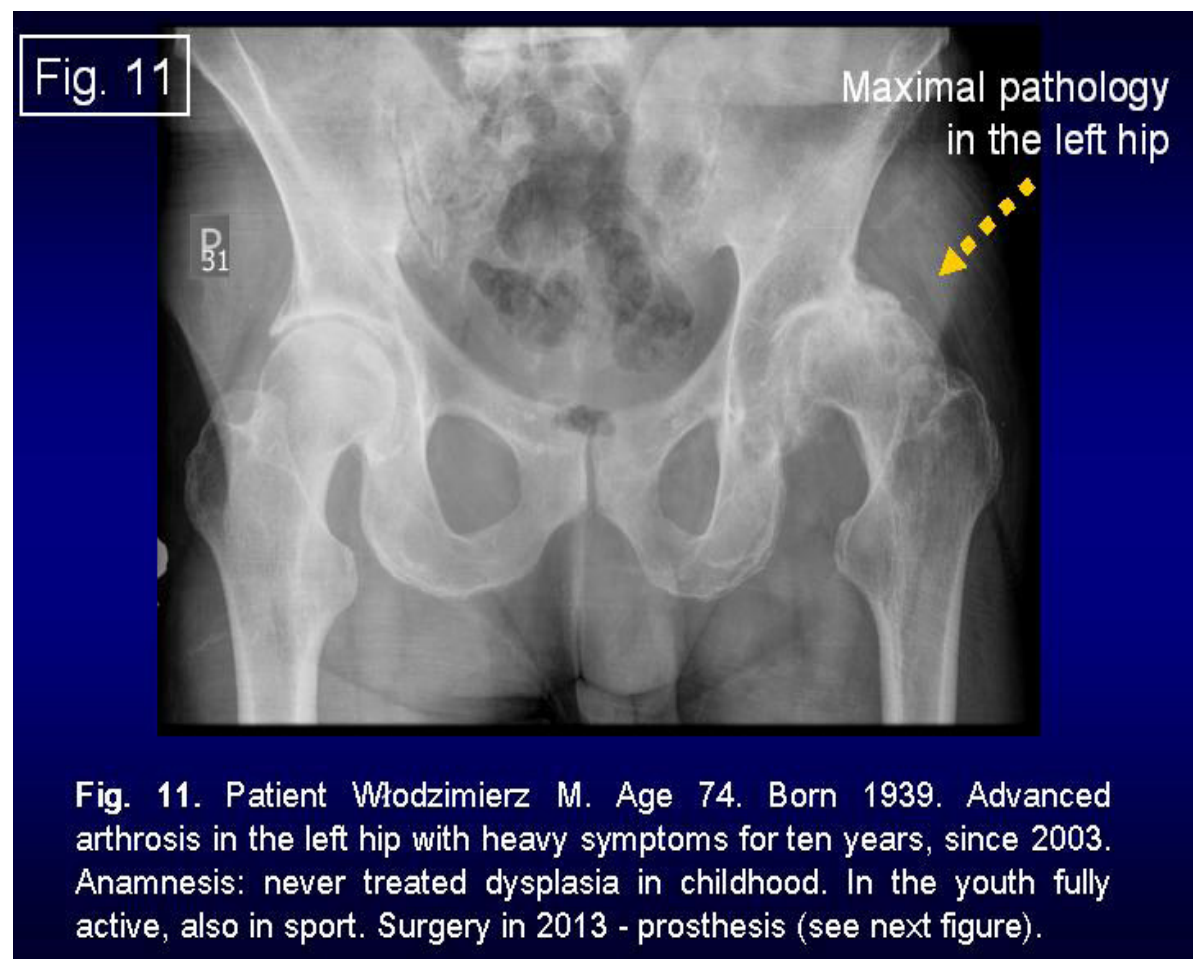

Fig 11. Patient Włodzimierz M. Age 74. Born 1939. Advanced arthrosis in the left hip with heavy symptoms ten years, from 2003. Anamnesis: never treated dysplasia in childhood. In youth period of life full active also in sport.

Operation in 2013 - prosthesis (see next figure).

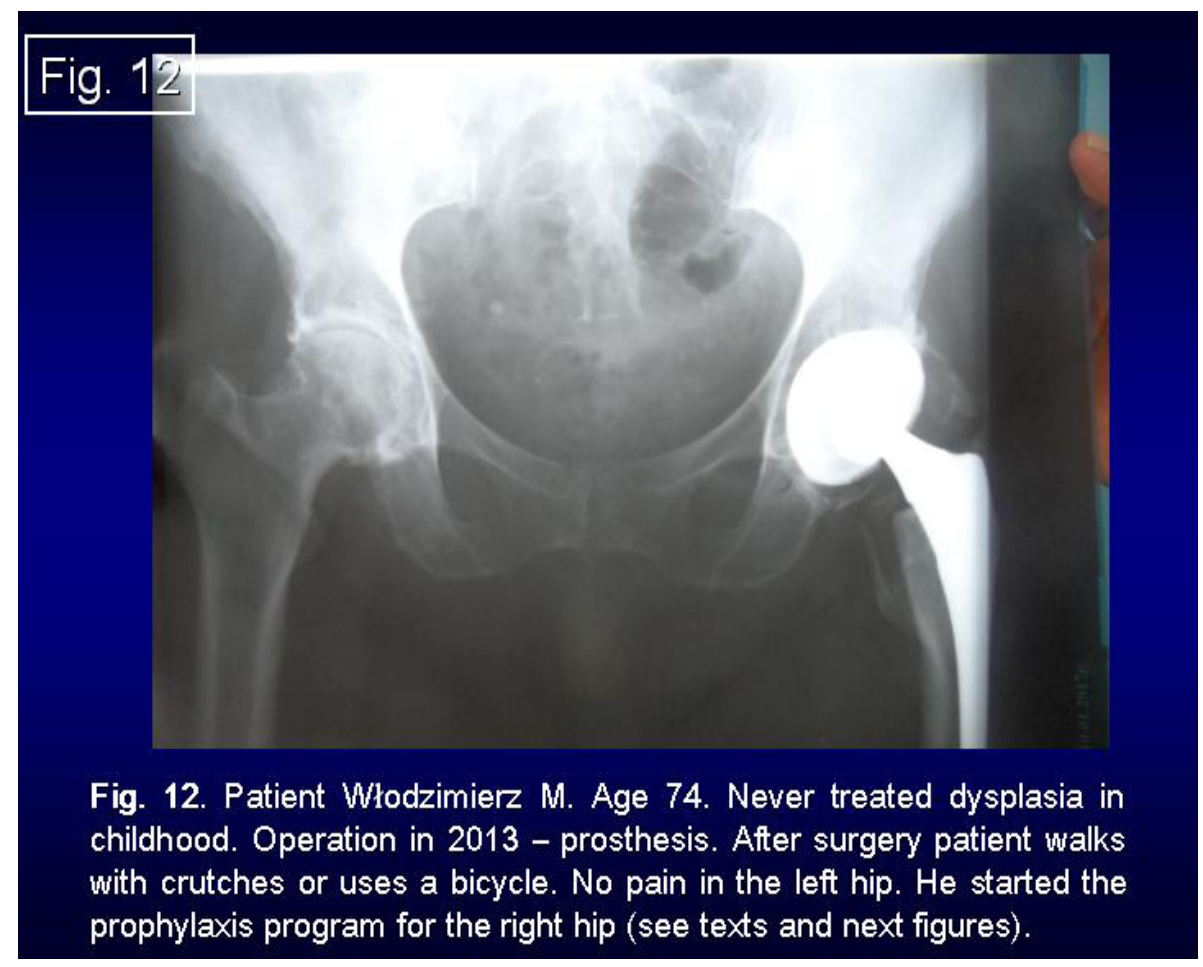

Fig 12. Patient Włodzimierz M. Age 74. Never treated dysplasia in childhood. Operation in 2013 - prosthesis. After surgery patient's gait is with sticks or he use bicycle. No pain in left hip. He start with prophylaxis program for right hip (about it - see texts and next figures). 
Problem of Hips. Children - Dysplasia. Adults - "Imperfect Hips" and Arthrosis. Methods of Prophylaxis and Therapy in Every Age

Adult patients - symptoms of "Imperfect Hip" in the right hip. Information about "Syndrome of Permanent Standing 'at ease' on the Right Leg”

During the years 1984 - 2007 in research on idiopathic scoliosis [8] [9] [14] author (T. Karski) found that patients with scoliosis had the habit to stand 'at ease' only or mostly on the right leg [8] [9] [14] [20] [21] [25].

This phenomenon was published as first in article in Orthopädische Praxis / Germany in 1996 - T. Karski Kontrakturen und Wachstumstörungen im Hüftund Beckenbereich in der Ätiologie der sogenannten "idiopatischen Skoliosen" - biomechanische Überlegungen. Orthopädische Praxis 32, 3 (1996) 155-160) and next in first article in English in 2002 Karski T.: Etiology of the so-called "idiopathic scoliosis". Biomechanical explanation of spine deformity. Two groups of development of scoliosis. New rehabilitation treatment. Possibility of prophylactics, Studies in Technology and Informatics, Research into Spinal Deformities 4, Vol. 91., IOS Press 2002, Amsterdam, Berlin, Oxford, Tokyo, Washington DC, 37-46.

Permanent standing on the right leg start to be from the 2 - nd year of life and is the cause of scoliosis in two types: in "S" scoliosis, 1st ethiopathogical group (epg), together with walking, and in "C" 2nd/A epg as well "S" 2nd/B epg scoliosis. In next years 1996 till 2019 there were many publications - mostly in USA. About scoliosis was also publication in Internal Medicine Journal (USA, 2019).

Why the children and adults has the habit to stand 'at ease' on the right leg. To understand this habit we must return to the "Syndrome of Contractures and Deformities" (SofCD). In this Syndrome there is also difference in movements of hips. The movements of right hip is limited - especially adduction in straight position, internal rotation and extension - this last movement mostly in both hips. These limited movements in the right hip make that this hip is more stable and because of this is frequent taken for standing.

Permanent standing 'at ease' on the right leg lead not only to scoliosis and next to degenerative changes in the spine but also to arthrosis of the right hip, what is subject of this paper.

Permanent standing on the right leg is the cause of overstress in right hip, right knee and shank.

The right leg is used for standing from the early childhood and maintained over years. Such standing on the right leg is because of two reasons, described now in details:

$\mathbf{1}$ / the right hip has smaller adduction in the strait position of the joint. In some children examined for scoliosis we observed even abduction contracture $(-) 5$ to $(-10)$ degree. Here we repeat - this limitation of movements of the right hip is one of symptoms of SofCD,

2 / therefore to stand on the right leg 'at ease' is more comfortable in comparison to standing on the left one.

The limitation of adduction is only in strait position of the right hip joint is one of the eight symptoms of "Sydnrome of Contractures and Deformities" ( $\mathrm{H}$. Mau, T. Karski, J. Karski). This is a new discovery in the "orthopedic research", because till 1995 we have spoken only about "limitation of abduction of the left hip" as the first symptoms of Developmental Dysplasia of the Hip (DDH).

In new research we explain the problem of abduction contracture of the right hip or only limitation of adduction in straight position of this joint as the "biomechanical reasons" in development of various motor system abnormities.

\section{Clinical Symptoms of "Imperfect Hips" Left or Right Side}

Everybody, over the all years of life, and special very intensive in adult period of life, lose abduction, internal rotation and extension of the hips.

Some adults patients presented "such restriction of movements" in left hip ([N] - 30\% of cases), others in the right hip ([N] - 70\% of cases). The pain syndrome in the left hip with all sign of degenerative illness is an effect of not fully cured dysplasia in childhood, what was mentioned above [1] [2] [3] [4] [5] [6] [7] [10] [11] [12] [24] [25] [26] [27] [28] [29] 30] [31]. 
Problem of Hips. Children - Dysplasia. Adults - "Imperfect Hips" and Arthrosis. Methods of Prophylaxis and Therapy in Every Age

In the right hip the pain appears as result of "Syndrome of (permanent) Standing 'at ease' on the Right Leg" (SofSRL). The problem is connected with "the cumulative time of standing on the right leg" over years [16] [17] [18] [19] [21] [22] [23] [24] [25]. This "new syndrome" - SofSRL is presented on Symposia and Congresses from the 1997. It is also the subject of publication in Locomotors System, Journal in Czech Republic (2018) and in many others articles published in USA (2009 - 2019).

The first symptoms of insufficiency of the hips are: pain - very often morning by first steps. The pain is localized in inguinal region, sometimes on lateral side of the hip, in some patients on medial upper part of femur, sometimes the pain radioed to the knee. In some cases, the pain disappeared for weeks, or even for some months and because of this is not treated seriously by patients as was mentioned above.

Almost 30 years of observations, has given confirmation that this phenomenon, at the beginning of insufficiency of hips is percept by patients as only temporary problem, and it is seen nearly by every patients. Appearance and disappearance of pain take place without any visible causes. In some cases of illness the pain can be only after long wandering in mountains, after overstressed in sport like jogging, football play, sometimes after hard work.

Sometimes patients complain of limping. We repeat, that in the beginning period of illnesses all these pathological phenomenon can appear only for a short time. This statement is very important from clinical point of view - because in this "unclear clinical period of illness" - we should introduce the prophylactics methods. The internist doctors, general doctors, orthopaedic surgeons should be familiarised with the "Syndrome of Standing on the Right Leg" and with prodromal / preliminary symptoms of "Imperfect Hips" and in this early period of illnesses should recommended the prophylactics method to reduce the symptoms of "Imperfect Hips", beginning phase of hip arthrosis.

\section{Radiological Symptoms of "Imperfect Hips"}

As mentioned in the chapter above - the radiological symptoms are connected with incorrect congruency of the femoral head in the acetabulum [18] [19] [21] [22] [23] [24] [25] [26].

In situation, when all angles and shape of the proximal end of femur are proper - the hip joint, in spite of these, can be not develop correctly. It is in situation if the femur's head is not proper placed in the acetabulum. Exactly observation of their X-ray pictures show in many patients normal Wiberg angle, normal CCD (Centrum Collum Diaphysis) angle, normal AT (Antetoriosn) angle and even good or almost good developed roof, but the congruence of "femoral head into acetabulum" can be not proper. The distance between femoral head to the bottom of acetabulum can be bigger than the distance of femoral head to the roof (Fig. 7, 12). Such hips are permanent overstressed during gait in every step - what is also confirmed in Literature. Many authors explain that during gait - in stance phase - the loading on the femoral head is "four times bigger that the weight of the person" [22] [23] [24] [25] [26] [27] [28] 29] [30] [31].

\section{The Prophylaxis and Treatment of "Imperfect} Hips" by Physiotherapies Methods

The aim of treatment and prophylaxis (in many cases therapy and prophylaxis are equal) is to restore the full movement of the hips and changing the load during standing and during gait. Such therapy should be continues in every step and in every time of day and night over many years of life. The article presents exercises elaborated in the time over 30 years and there are very simply for patients (Fig 16, 17, 18, 20). Additionally we can use in therapy: jonophoresis, diadynamic, laser, as well exercises in geothermal water (Fig. 21).

In all cases with pre-arthrosis symptoms we received sufficient or good results. It's mean - no pain or less pain, increasing of range of movements, better gait, better quality of life, better possibility in job and at home. In full develop arthrosis cases - we receive "prolonged period" of better function in the hip in gait, and no pain at night. In this last group of patients the hip replacement could be prolonged for some years (Fig. 11). 
Problem of Hips. Children - Dysplasia. Adults - "Imperfect Hips" and Arthrosis. Methods of Prophylaxis and Therapy in Every Age

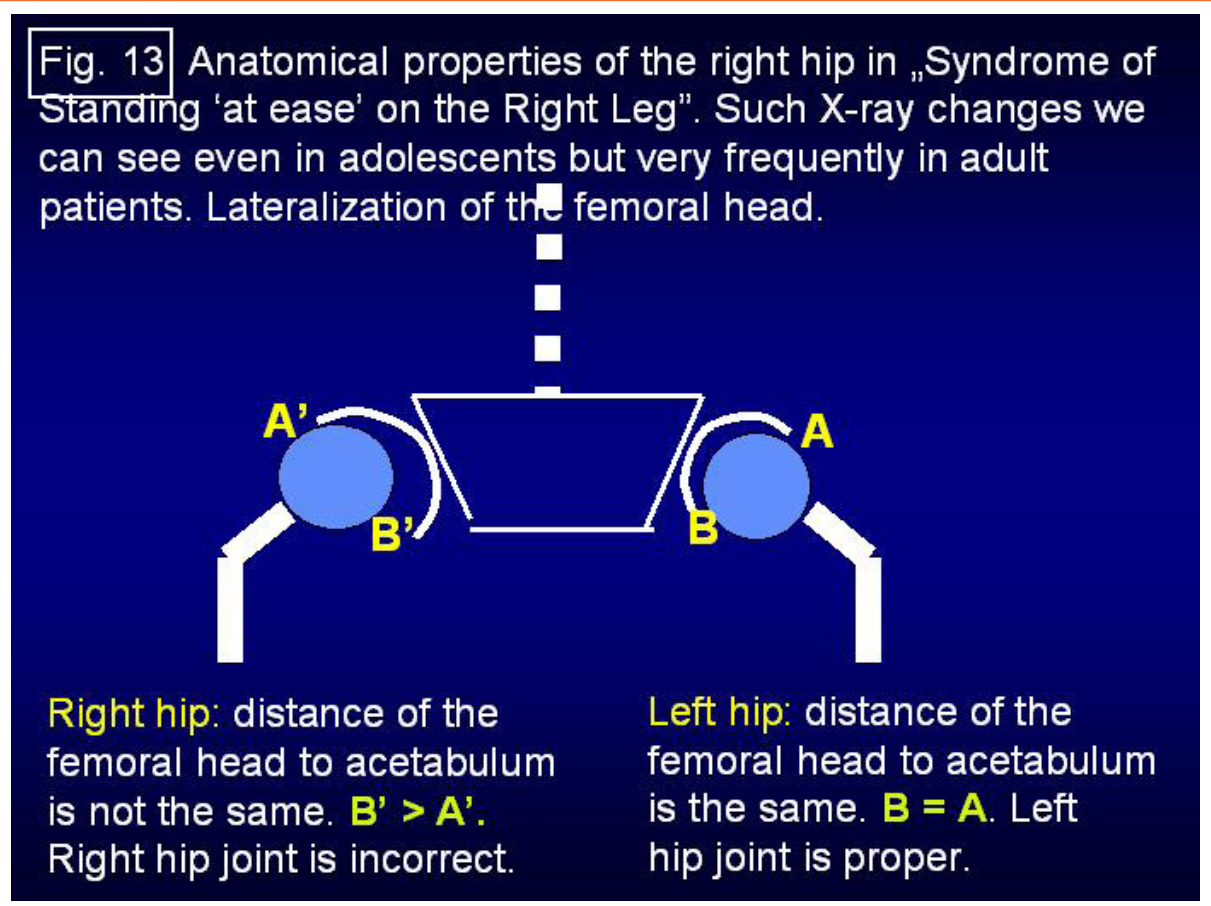

Fig 13. Anatomical properties of the right hip in "Syndrome of Standing 'at ease' on the Right Leg". Such X-ray changes we see even in youth period of life but very frequently in adults patients. Lateralization of the femoral head. Right hip: distance of the femoral head to acetabulum is not the same. $B^{\prime}>A$. Right hip joint is incorrect.

Left hip: distance of the femoral head to acetabulum is the same. $B=A$. Left hip joint is proper.

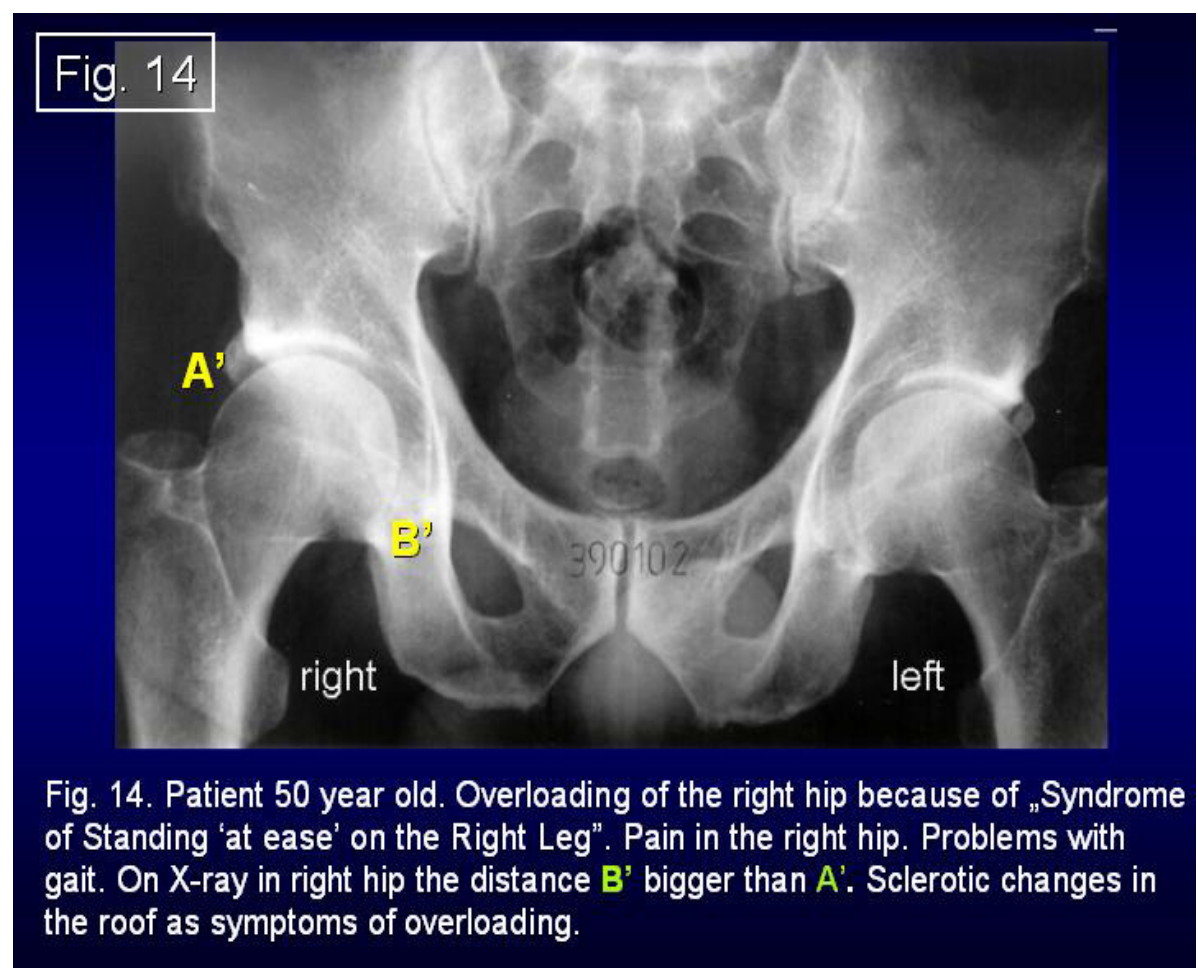

Fig 14. Patient 50 year old. Overloading of the right hip because of "Syndrome of Standing 'at ease' on the Right Leg". Pain in the right hip. Problems with gait. On X-ray in right hip the distant B' is bigger than A'. Sclerotic changes in the roof as symptoms of overloading. 
Problem of Hips. Children - Dysplasia. Adults - "Imperfect Hips" and Arthrosis. Methods of Prophylaxis and Therapy in Every Age

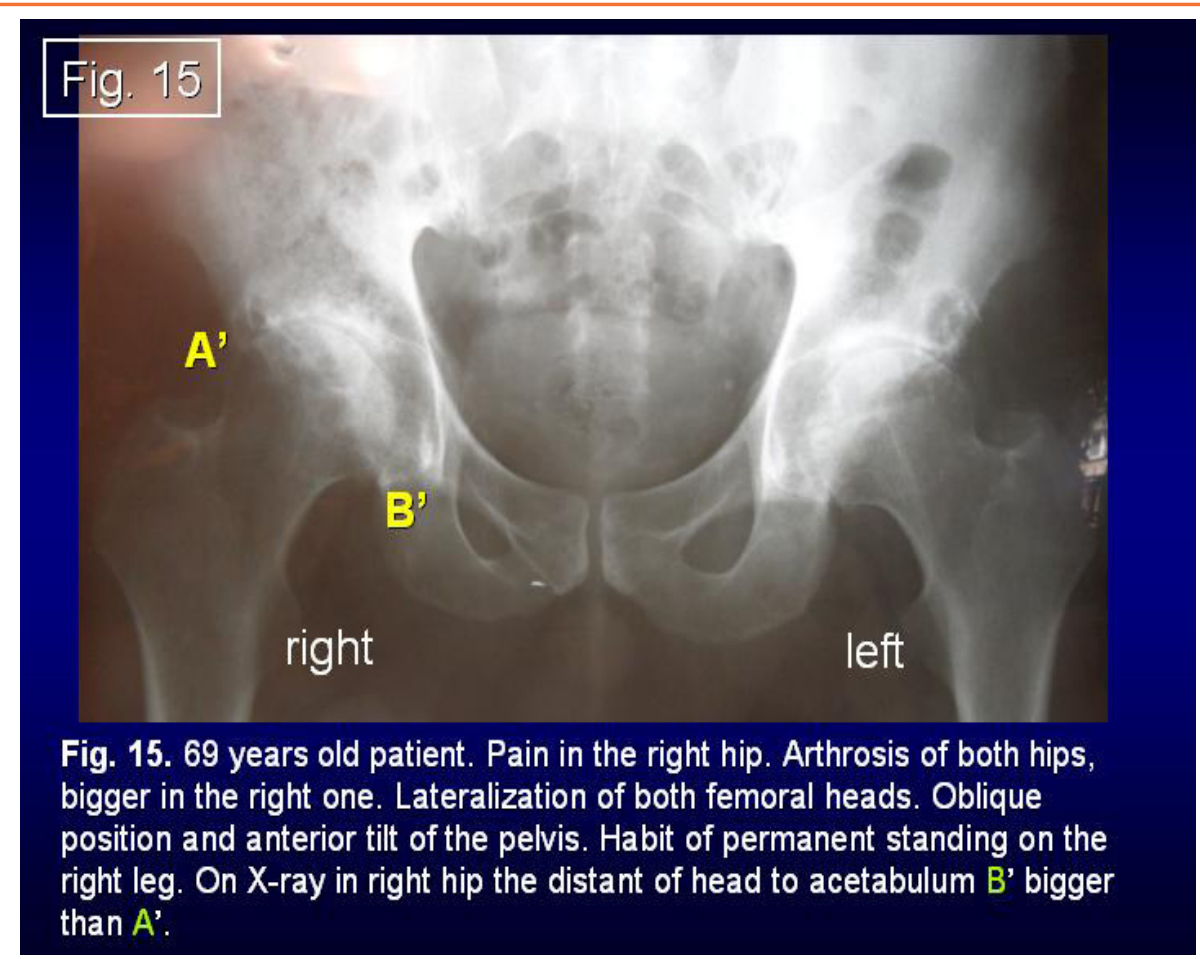

Fig 15. Patient 69 year old. Pain in right hip. Arthrosis of both hips, bigger in right joint. Lateralization of both femoral heads. Oblique position and anterior tilt of the pelvis due to the habit of permanent standing on the right leg. On X-ray in right hip the distant of head to acetabulum $B^{\prime}$ is bigger than $A^{\prime}$.

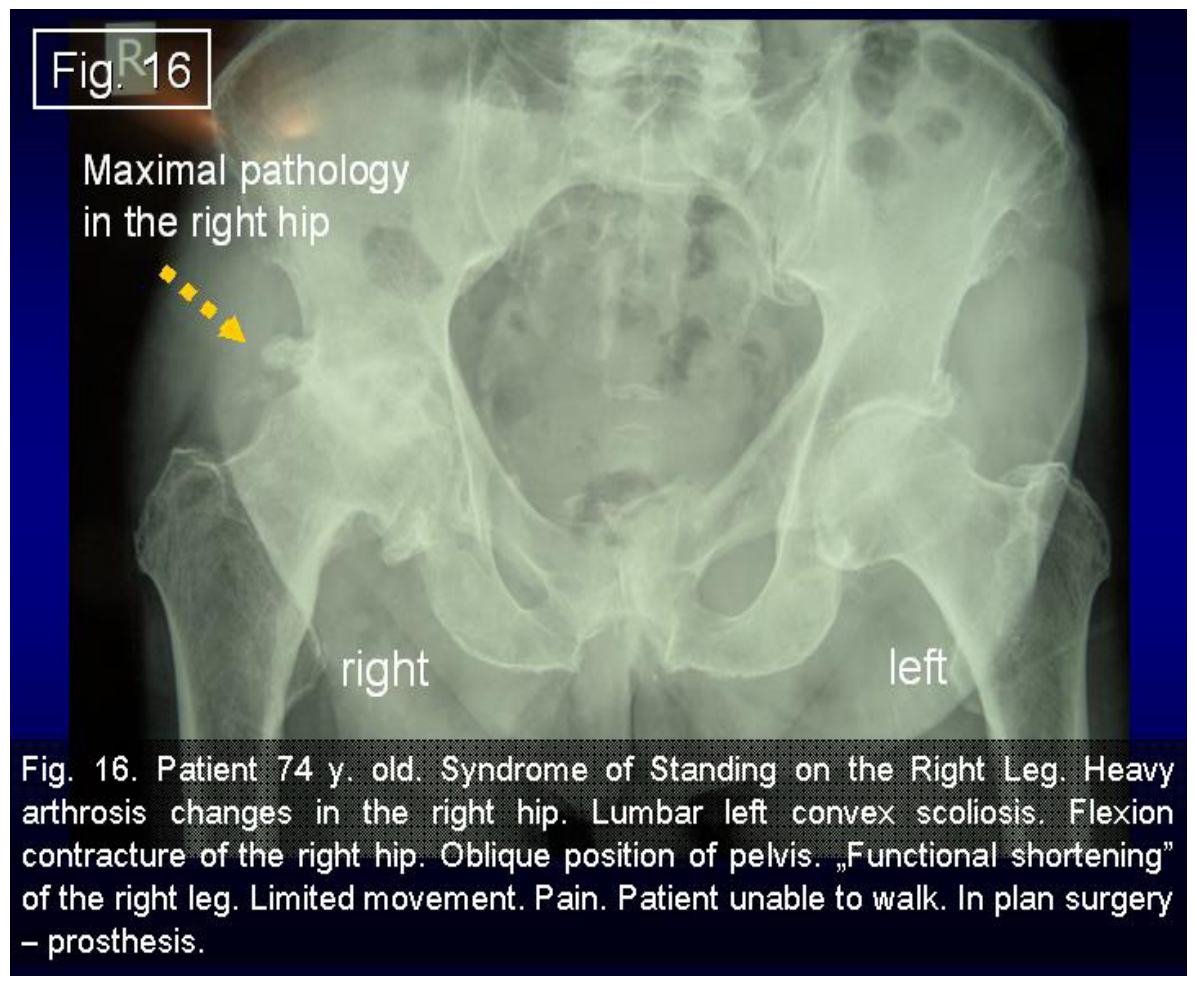

Fig 16. Patient 74 y. old. Syndrome of Standing on the Right Leg. Heavy arthrosis changes in the right hip. Lumbar left convex scoliosis. Flexion contracture of the right hip. Oblique position of pelvis. "Functional shortening" of the right leg. Limited movement. Pain. Patient unable to walk. In plan surgery - prosthesis. 
Problem of Hips. Children - Dysplasia. Adults - "Imperfect Hips" and Arthrosis. Methods of Prophylaxis and Therapy in Every Age

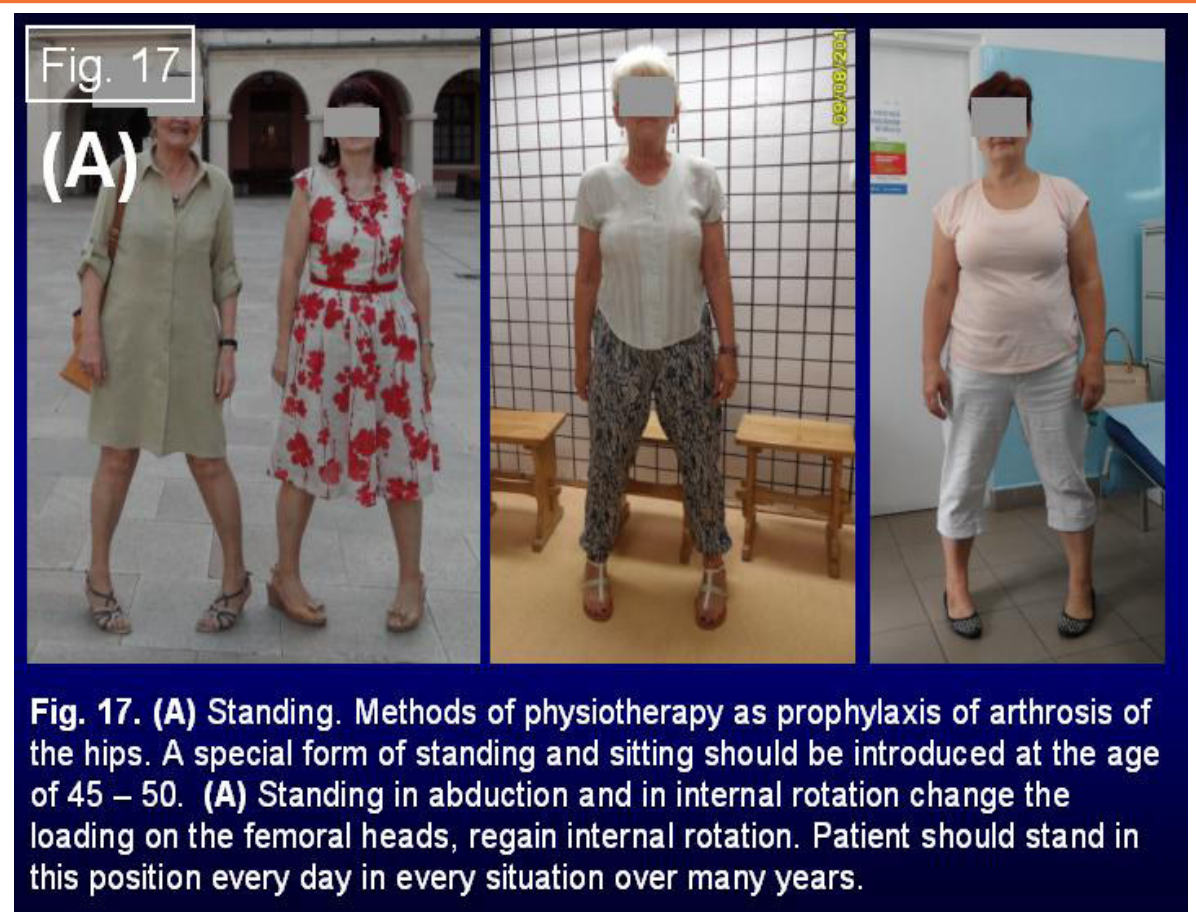

Fig 17. (A) Standing. Methods of physiotherapy as prophylaxis of arthrosis of the hips. Start with a special form of standing and sitting should be from $45-50 y$. of life. (A) Standing in abduction and in internal rotation change the loading on the femoral heads, regain internal rotation. Such standing should be done every day in every situation over many years.

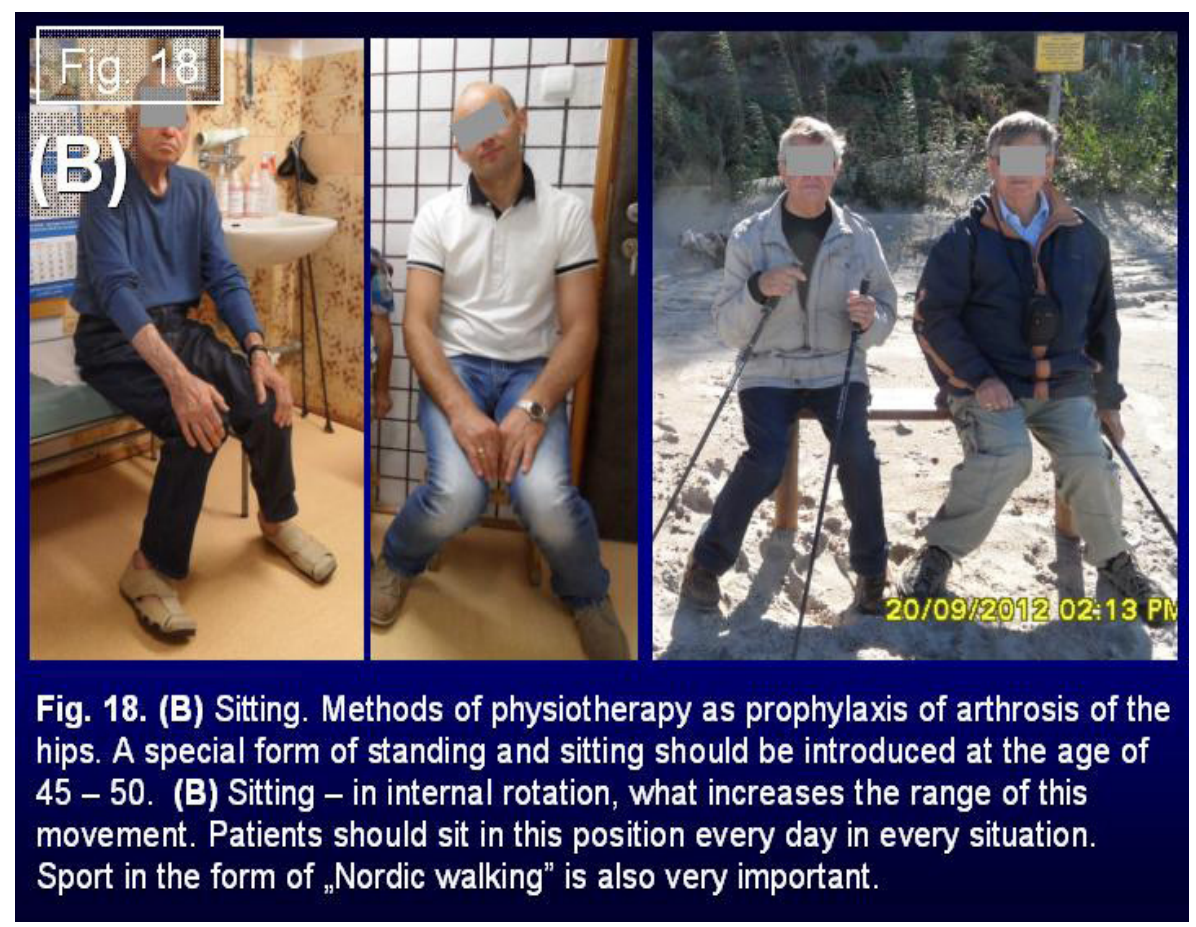

Fig 18. (B) Sitting. Methods of physiotherapy as prophylaxis of arthrosis of the hips. Start with a special form of standing and sitting should be from $45-50 y$. of life. (B) Sitting - in internal rotation, what increase range of this movement. Such sitting should be done every day in every situation. Also important gait in form of "Nordic walking". 
Problem of Hips. Children - Dysplasia. Adults - "Imperfect Hips" and Arthrosis. Methods of Prophylaxis and Therapy in Every Age

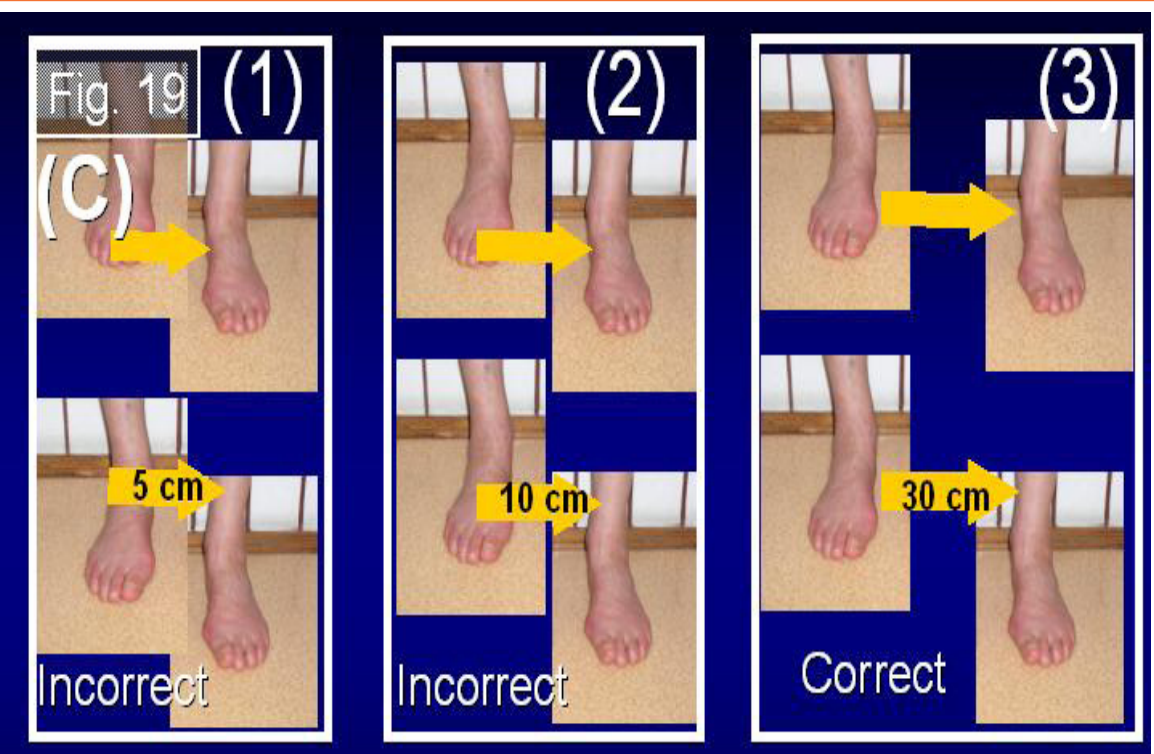

Fig. 19. (C) Walking. Methods of physiotherapy as prophylaxis of arthrosis of

the hips. Patients should walk with feet apart, never together. Such gait

prevents hip arthrosis. Gait (1) and (2) is not proper. Gait (3) is correct. Feet should be $30 \mathrm{~cm}$ apart. As an exercise - even $40 \mathrm{~cm}-50 \mathrm{~cm}$.

Fig 19. (C) Gait. Methods of physiotherapy as prophylaxis of arthrosis of the hips. Gait should be with feet apart, never feet together. Such gait is against arthrosis of the hips. Gait (1) and (2) is not proper. Gait (3) is correct. Feet should be - apart $30 \mathrm{~cm}$. As a personal gymnastic - apart even $40 \mathrm{~cm}-50 \mathrm{~cm}$.

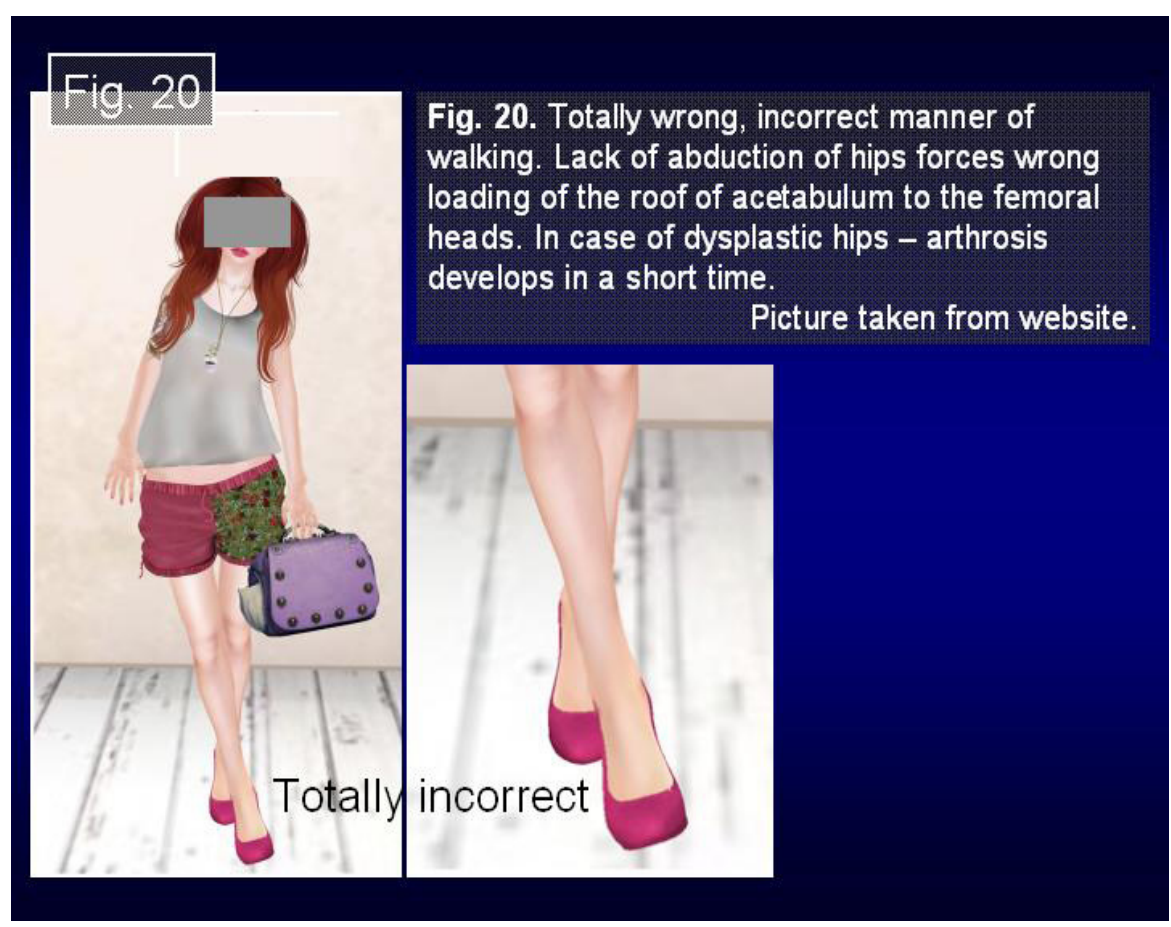

Fig 20. Totally wrong, incorrect manner of walking. Lack of abduction of hips "bring about" the wrong loading of the roof of acetabulum to the femoral heads. In case of dysplastic hips - develop in short time the arthrosis. Picture taken from USA Internet. 
Problem of Hips. Children - Dysplasia. Adults - "Imperfect Hips" and Arthrosis. Methods of Prophylaxis and Therapy in Every Age

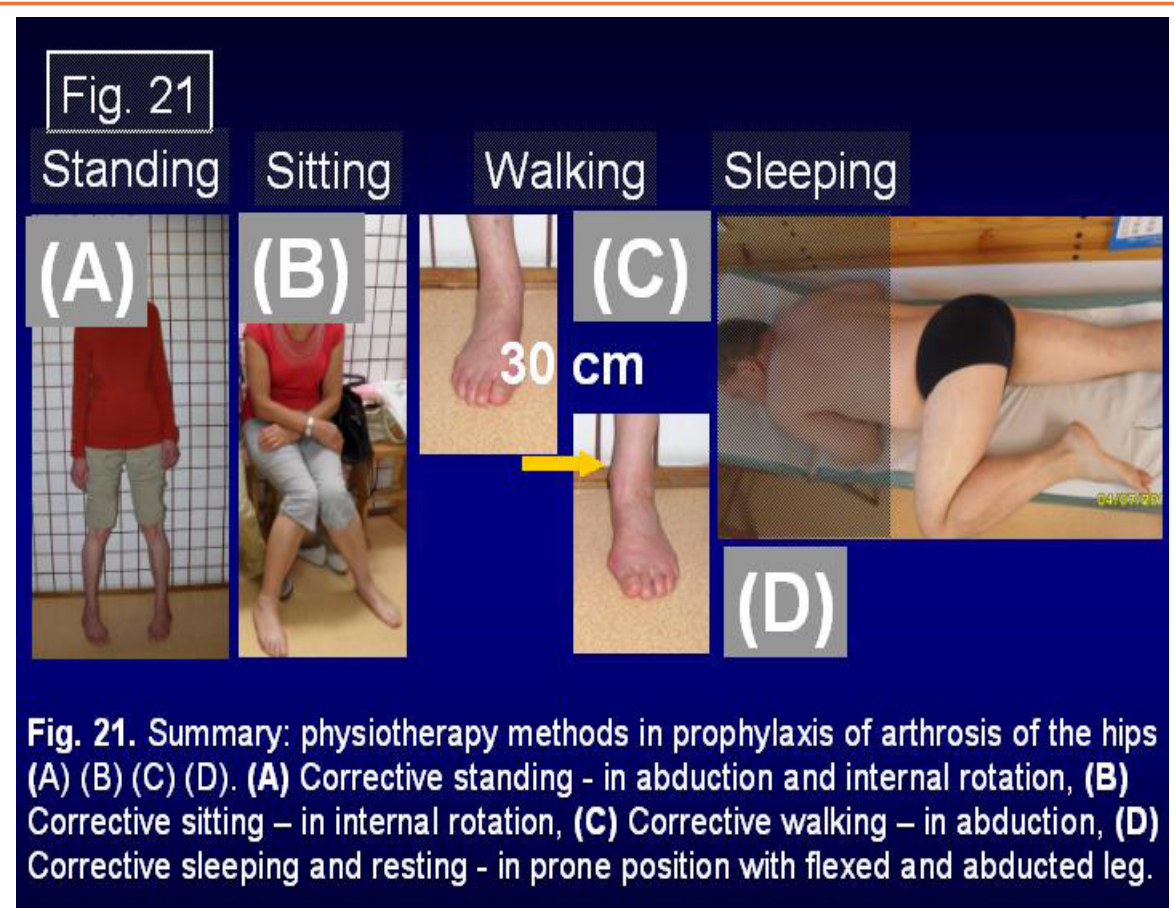

Fig 21. Summarized: methods of physiotherapy in prophylaxis of arthrosis of the hips $(A)(B)(C)$ (D). (A) Corrective standing - in abduction and internal rotation, (B) Corrective sitting - in internal rotation, (C) Corrective walking - in abduction, (D) Corrective sleeping and rest - in prone position with flexed and abducted leg.

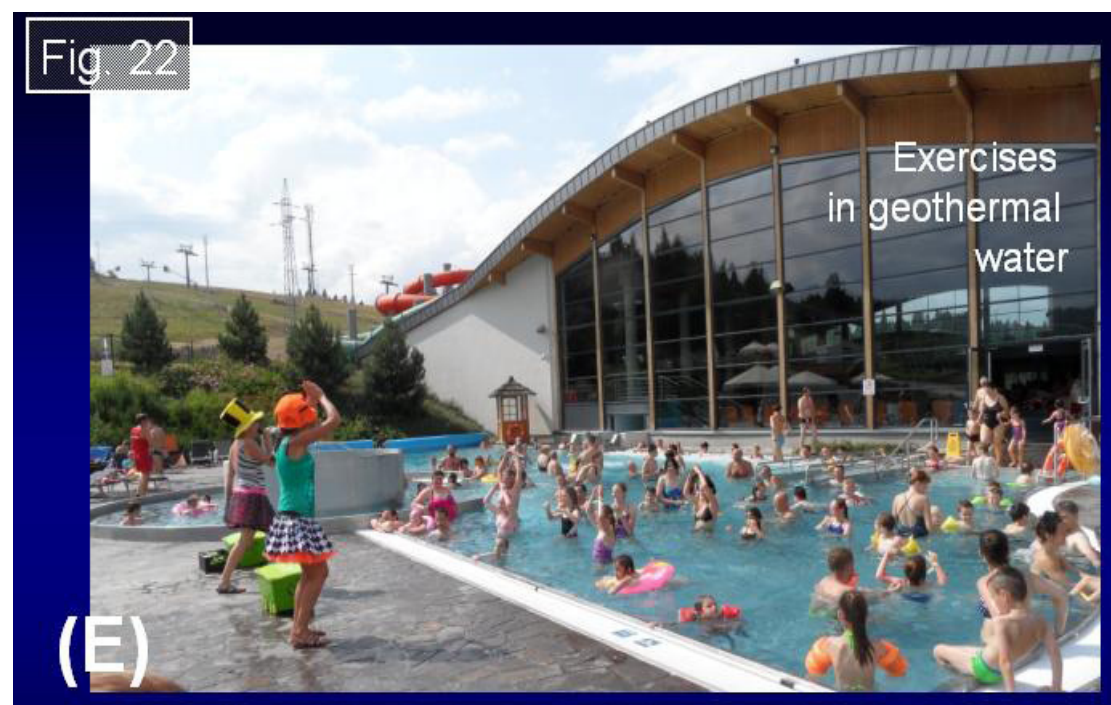

Fig. 22. Summary: physiotherapy methods in prophylaxis of arthrosis of the hips $(A)(B)(C)(D)(E)$. Realization of all points: $(A)(B)(C)(D)$ and additionally $(E)$ exercises in geothermal water to receive full abduction, full internal rotation and extension of both hips. Picture taken in Rehabilitation Geothermal Center in Poland.

Fig 22. Summarized: methods of physiotherapy in prophylaxis of arthrosis of the hips $(A)(B)(C)(D)$

(E). Realization of all points: $(\boldsymbol{A})(\boldsymbol{B})(\boldsymbol{C})(\boldsymbol{D})$ and additionally $(\boldsymbol{E})$ exercises in geothermal water to receive full abduction, full internal rotation and extension of both hips. Picture taken in Rehabilitations Geothermal Center in Poland. 
Problem of Hips. Children - Dysplasia. Adults - "Imperfect Hips" and Arthrosis. Methods of Prophylaxis and Therapy in Every Age

\section{RESUlTS OF PHYSIOTHERAPY}

To compare the results in various groups of patients we had all the patients [(N) $612-100 \%]$ divided in three groups:

(1) patients (55\%) primary with normal gait but with temporary pain as result of hip insufficiency,

(2) patients (30\%) with permanent pain but without visible radiological changes in hips,

(3) patients (15\%) with permanent pain, limping and advanced arthrosis symptoms in X-ray examination.

In first group (55\% from whole group) after new rehabilitation the patients receive long lasting good results - no pain over years, normal walking, good function of legs in every day situations. Many of these patients make sport ski, bicycle, like before.

In second group (30\% from whole group) the patients informed that after some month of such therapy, symptoms of insufficiency of the hips - pain and limitation of movements - were smaller or even disappear for longer time. They inform about better walking and better function at work and at home.

In third group (15\% from whole group) the patients walked better, but only for some times - smaller pain sometimes for 6 month or even 1 - 3 year. The patients from this group underwent surgery - implantation of artificial joints as the definitive therapy.

\section{Discussion}

The article try to answer in which situation can develop "imperfect hips" and arthrosis in older persons. On own experience we can say that in the causes of "imperfect hips" on first place is not fully cured dysplasia. In some cases wrong or incorrect treated dysplasia in children can be the cause even necrosis of femoral head and in older years the "imperfect hips" and arthrosis develop in very short time.

In persons, who had in child's time the Perthes disease - here we explain - this illness appeared in age of $4-10$ because of jumping on the hard floor - very frequently develop hip arthrosis in older age.

Other illness leading to arthrosis is the epiphyseolisis of femoral head in children in age of $12-15$ years.
Other causes of arthrosis of the hips can be post traumatic necrosis of the femur head. In adults the osteoporosis is very frequently the cause of arthrosis.

In this article we want to indicate quite new abnormities leading to arthrosis. There are the cases with "lateralization of femoral head" in left hips, if the dysplasia was not cured enough and in right hip because of permanent standing on the right leg in this new "Syndrome of Standing 'at ease' on the Right Leg". In these all cases appears limitation of movement of affected hip. A special dangerous for hip is limited internal rotation of the joint. On basis of our experiences we can say - that separate "limitation of movements of the hip" can be the cause of arthrosis. It also explain that regain of the movements mean regret of the hip illness. Well, physiotherapy in early period of hip illness, in phase of "imperfect hips", before "period of arthrosis" give long lasting good results.

\section{CoNCLUSIONS}

1/ The hips in newborn, babies and small children should be fully cured - that's mean in $100 \%$.

2/ Not fully treated hips with years will be only worse and next they receive the status - "Imperfect Hips", next "arthrosis".

3/ We should remember about "Syndrome of (permanent) Standing 'at ease' on the Right Leg" as the cause of so called-idiopathic scoliosis and of arthrosis of the right hip, even in primary good develop hips in childhood.

4/ In treatment, in spite of all physiotherapy methods, the most important is to change the loading of both hips in every step, in every day of life and restore the full movement of hips - abduction, internal rotation and extension.

5/ In prophylaxis we advices simply and very effective methods - changing the position of (A) standing - we advise standing in abduction 20 - 30 degree and in internal rotation 20-30 degree for every day situations, of (B) walking - we advise to keep in walking the feet apart 20 - $30 \mathrm{~cm}$, of (C) sitting - we advise sitting with the knee together and feet apart to restore internal rotation and of (D) sleeping - in flexion and abduction of ill hip. 
Problem of Hips. Children - Dysplasia. Adults - "Imperfect Hips" and Arthrosis. Methods of Prophylaxis and Therapy in Every Age

6/ Such physiotherapy is very simple, but should be used in every moment of life, over years. Only in realization of all recommendations can we receive good prophylactic effectiveness.

\section{Acknowledgement}

We would like to express our thanks words to Honorata Menet for correction of English in this paper.

\section{REFERENCES}

[1] Delaunay S, Dussault RG, Kaplan PA, Alford BA.: Radiographic measurements of dysplastic adult hips. Skeletal Radiol 1997;26:75-81.

[2] Dunn P. Congenital postural deformities: further perinatal associations. Proc. R. Soc. Med 1974;67:1174-8.

[3] FredensborgN,Nilsson B.Thejointspacein normal hip radiograms. Radiology 1978;126:325-6.

[4] Ipavec M., Brand R.A., Pedersen D.R., Mavcic B., Kralj-Iglic V., Iglic A.: Mathematical modeling of stress in the hip during gait. Journal of Biomechanics. 32 (1999), 1229 - 1235

[5] Karski Tomasz: Wczesne leczenie dysplazji stawu biodrowego (Early treatment of dysplasia of hip joint). Chirurgia Narządu Ruchu i Ortopedia Polska, 1988, LIII, 2, stron 6

[6] Karski Tomasz, Jacek Karski, Jarosław Kałakucki: Minimal incongruence of the hip joint at youth and adults treated and not-treated because of DDH in baby period. In: Second Annual International Conference SICOT/SIROT 2003. Cairo, September 10-13, 2003. Abstr, [b. pag.] SFS8-H.

[7] Karski Jacek, Długosz Mariusz, Kałakucki Jarosław, Karski Tomasz: "Science and opinion - knowledge and ignorance (Hippocrates) on examples in paediatric orthopaedics" - Blount disease, X-knee deformity, chronic pain in shank and foot by owners of small cars (P. 2). Pohyb. Ustr. (Czech Republic) 2008 R. 16 č. 3/4 suppl., s. 286-288.

[8] Karski Tomasz: Kontrakturen und Wachstumstö rungen im Hüft- und Beckenbereich in der Ätiologie der sogenannten i“diopatischen
Skoliosen" - biomechanische Überlegungen Orthopädische Praxis 32, 3 (1996) 155-160

[9] Karski Tomasz: Etiology of the so-called "idiopathic scoliosis". Biomechanical explanation of spine deformity. Two groups of development of scoliosis. New rehabilitation treatment. Possibility of prophylactics, Studies in Technology and Informatics, Research into Spinal Deformities 4, Vol. 91., IOS Press 2002, Amsterdam, Berlin, Oxford, Tokyo, Washington DC, 37-46.

[10] Karski Jacek, Karski Tomasz, Kałakucki Jaroslaw, Wojtowicz Krzysztof : Minimal incongruence of the hip joint as the biomechanical cause of overloading of the femoral head. Explanation of reasons of the "painful hip" at youth and adults and development of coxarthrosis incipiens. Magyar. Traumatol. Ortop. 2003, Suppl. p. 80-81.

[11] Karski Jacek, Kałakucki Jarosław, Karski Tomasz, Wójtowicz Krzyszof: Incongruence of hip joint in treated and untreated persons with DDH in the baby period. Contribution to the knowledge of the very early stage of hip arthrosis (coxarthrosis incipiens). (Niezborność stawu biodrowego u osób leczonych w dzieciństwie z powodu wrodzonej dysplazji biodra i u osób nieleczonych. Przyczynek do wiedzy o wczesnych fazach koksartrozy (coxarthrosis incipiens).). Annales UMCS Sect. D 2005 vol. 60 nr 1, s. 32-39

[12] Karski Tomasz, Jarosław Kałakucki, Jacek Karski: Relationship of "syndrome of contractures" in newborns with the development of the so-called idiopathic scoliosis, World J. Pediatr. / China, 2007 vol. $3 \mathrm{nr}$ 4, s. 254-259, bibliogr. 38.

[13] [13] Karski Tomasz: Biomechanical Etiology of The So-Called Idiopathic Scoliosis (1995 - 2007) - Connection with "Syndrome of Contractures" Fundamental Information for Paediatricians in Program of Early Prophylactics / Journal of USChina Medical Science, USA, May 2011, Volume 8, No 78

[14] Karski Tomasz: Biomechanical Etiology of the Socalled Idiopathic Scoliosis (1995 - 2007). Three Groups and Four Types in the New Classification, 
Problem of Hips. Children - Dysplasia. Adults - "Imperfect Hips" and Arthrosis. Methods of Prophylaxis and Therapy in Every Age

Journal of Novel Physiotherapies, OMICS Publishing Group, USA, 2013, S2, 6 pages

[15] Karski Jacek, Karski Tomasz: So-Called Idiopathic Scoliosis. Diagnosis. Tests Examples of Children Incorrect Treated. New Therapy by Stretching Exercises and Results, Journal of Novel Physiotherapies, OMICS Publishing Group, USA, 2013, 3-2, 9 pages

[16] Karski Jacek, Karski Tomasz, Pyrc Jarosław, Kulka Małgorzata: Deformations of the feet, knees, hips, pelvis in children and adults with minimal brain dysfunction. causes. treatment. Prophylaxis. Locomotor System vol. 23, 2016, no. 2 / Pohybové Ustrojí , ročník 23, 2016, č. 2

[17] Karski Tomasz, Karski Jacek, Karska Klaudia, Karska Katarzyna, Menet Honorata: Patologie kyčle, kolena, hlezna a páteře $\mathrm{v}$ důsledku habituálního postoje "pohov" na pravé dolní končetině / Pathology of the hip, knee, shank and spine due to the habit of standing 'at ease' on the right leg. Locomotor System vol. 24, 2017, no. 2 / Pohybové Ustrojí, Czech Republic, ročník 24,2017, č. 2

[18] Karski Tomasz, Karski Jacek, Karska Klaudia, Karska Katarzyna, Menet Honorata: Prophylaxis of Illnesses and Deformations of Hips, Knees, Feet and Spine-An Important Aim of Physiotherapists, Pediatricians and General Doctors, Physical Medicine and Rehabilitation - International. Open. Austin Publishing Group. USA. Phys Med Rehabil Int 5(3): id 1147 (2018) - Page - 03

[19] Karski Tomasz, Karski Jacek, Karska Klaudia, Karska Katarzyna and Menet Honorata: Pediatric Prophylaxis Program of Motor System Deformations and Illnesses in Children. Problems of Spine, Hips, Knees and Feet, EC PAEDIATRICS, UK. Review Article. EC Paediatrics 7.7 (2018), pages 15 .

[20] Karski Tomasz: So-Called Idiopathic Scoliosis in New Classification. Prophylactics and Therapeutic Aims for Orthopedic Surgery and for General Medicine. Open Access Journal of Internal Medicine. USA. ISSN: 2638-5279, Volume 1, Issue 2, 2018, PP: 30-39
[21] Karski Tomasz, Karski Jacek, Domagała Marian: "Syndrome of Contractures" According to Prof. Hans Mau; Problems of Shanks, Knees, Hips, Pelvis and Spine; Children, Adolescents, Adults, Diagnosis, Treatment. Surgical Science. 2019, 10, 24-38. http://www.scirp.org/journal/ss. ISSN Online: 2157-9415. ISSN Print: 2157-9407. USA. 2019. DOI: 10.4236/ss.2019.101004 Jan. 24, 201924 Surgical Science. Pages 24 - 38

[22] Karski Jacek, Karski Tomasz: "Imperfect hips" As a Problem at an Older Age. Early and Late Prophylactic Management before Arthrosis. Jacobs Journal of Physiotherapy and Exercises / USA / Texas. 2016, (2) 1: 015, Pages 7

[23] Lanyon P, Muir K, Doherty S, Doherty M.: Age and sex differences in hip joint space among asymptomatic subjects without structural change: implications for epidemiologic studies. Arthritis Rheum 2003;48:1041-6.

[24] Lequesne M, J Malghem, E Dion: The normal hip joint space: variations in width, shape, and architecture on 223 pelvic radiographs. Ann Rheum. / France / Dis. 2004:63:1145-1151.

[25] Rigo J., Szepesi K., Meszaros T.: in Book with contents with material of "Symposium - latest achievements in orthopaedics and in paediatric orthopaedics. Prophylactic program important in 'Bones and Joint Decade 2000 - 2010", Lublin, $2009,133-223$

[26] Roach KE, Persky V, Miles T, Budiman-Mak E. Biomechanical aspects of occupation and osteoarthritis of the hip: a case-control study. J. Rheumatol. 1994;21:2334-40.

[27] Rosegger H; Steinwendner G, Transverse fetal position syndrome a combination of congenital skeletal deformities in the newborn infant. (German) Pädiatrie und Pädologie [Padiatr Padol], ISSN: 0030-9338, 1992; Vol. 27 (5), pp. 125-127; Publisher: Springer; PMID: 1437228;

[28] Spector T. Radiographic criteria for epidemiologic studies of osteoarthritis. J. Rheumatol 1995;22 (suppl 43):46-7. 
Problem of Hips. Children - Dysplasia. Adults - "Imperfect Hips" and Arthrosis. Methods of Prophylaxis and Therapy in Every Age

[29] Tallet J.M., Hornung H., Bollini G., Jacquemier M.: [30] Thelin A, Jansson B, Jacobsson B, Strom H. Traitement chirurgical de la luxation congenitale de hanche du grand enfant; analise des resultats. Revue de Chirugie Orthopedique, 1986, 72, 367375 Coxarthrosis and farm work; a case-referent study. Am J. Ind. Med. 1997;32:497-501.

[31] www.ortopedia.karski.lublin.pl

Citation: Karski Tomasz, Karski Jacek. Problem of Hips. Children - Dysplasia. Adults - "Imperfect Hips" and Arthrosis. Methods of Prophylaxis and Therapy in Every Age. Open Access Journal of Internal Medicine. 2019; 2(1): 7-25.

Copyright: (C) 2019 Karski Tomasz, Karski Jacek. This is an open access article distributed under the Creative Commons Attribution License, which permits unrestricted use, distribution, and reproduction in any medium, provided the original work is properly cited. 